Universidad deValladolid

\author{
PROGRAMA DE DOCTORADO EN CIENCIA E INGENIERÍA \\ AGROALIMENTARIA Y DE BIOSISTEMAS
}

TESIS DOCTORAL:

\title{
ANÁLISIS DE LA SOSTENIBILIDAD DE LA \\ CADENA DE VALOR AGROALIMENTARIA
}

\author{
Presentada por Cristino Alberto Gómez Luciano para \\ optar al grado de \\ Doctor por la Universidad de Valladolid
}

Dirigida por:

Dra. Beatriz Urbano López de Meneses 
"La innovación guiada por pequeños agricultores, adaptada a las circunstancias locales y sostenible para la economía y el ambiente, será necesaria para asegurar la seguridad alimentaria en el futuro"

Bill Gates. 


\section{ANÁLISIS DE LA SOSTENIBILIDAD DE LA CADENA DE VALOR AGROALIMENTARIA}

\section{Resumen}

La tesis tuvo por objeto analizar la sostenibilidad de los eslabones de la distribución, productor y consumo en la cadena de valor agroalimentaria de la República Dominicana. Se empleó la metodología de la cadena de valor y se utilizó una combinación de técnicas de investigación de mercados acorde con los objetivos propuestos. En el eslabón de la distribución se obtuvo una ausencia de gestión ambiental en la logística de la distribución. La sostenibilidad del eslabón productor depende del sector de actividad, siendo más sostenibles el plátano ecológico, el café y el aguacate. El consumo sostenible, para el caso de la sustitución de la carne en la dieta, presenta un lento avance en el país con respecto a países con mayor desarrollo económico. Los productos sustitutivos sostenibles deberán tener características similares a los productos que sustituyen para que los dominicanos estén dispuestos a comprarlos. Esta tesis contribuye mediante recomendaciones, implicaciones prácticas y futuras líneas de investigación al avance de la sostenibilidad de la cadena de valor agroalimentaria en contextos de desarrollo.

Palabras clave: Distribución, productor, consumo, indicadores de sostenibilidad, investigación de mercados.

\section{Abstract}

This research aims to analyse the sustainability of the distribution, production and consumption links in the Dominican Republic agrifood value chain. The value chain methodology was used and a combination of market research methods was applied. The results show that the distribution stage lacks of reverse logistic. The organic banano, coffee and avocado were most sustainable sectors. Sustainable consumption, as the substitution of the meat in the diet, is going slowly into the Dominican Republic with respect higher economic developed countries. Sustainable substitute characteristics are determinant for consumers to willing to purchase. This thesis contributes to value chain sustainability in developing frameworks with recommendations, practical implications and future research lines.

Key words: Supply chain, producer, consumption, sustainability indicators, market analysis. 


\section{ÍNDICE}

INTRODUCCIÓN

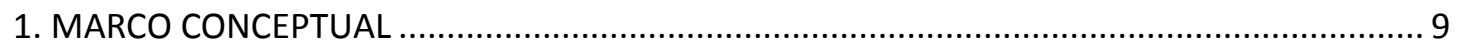

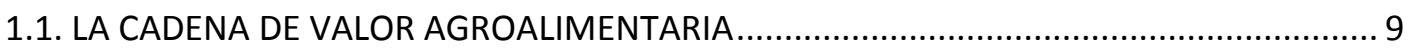

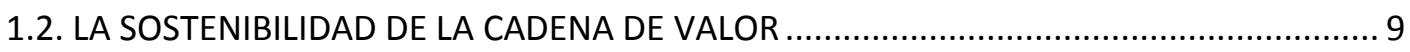

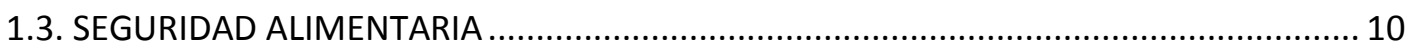

1.4. LA SOSTENIBILIDAD EN LA DISTRIBUCIÓN AGROALIMENTARIA ................................. 11

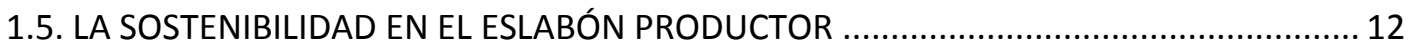

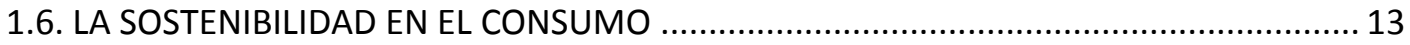

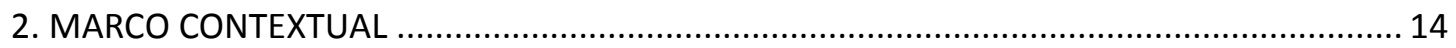

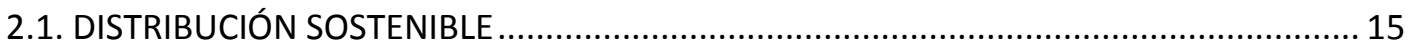

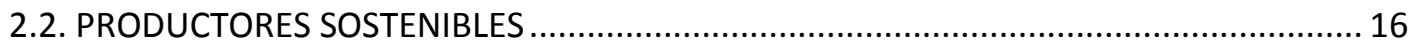

2.3. CONSUMO SOSTENIBLE PARA UNA CADENA DE VALOR SOSTENIBLE .......................... 17

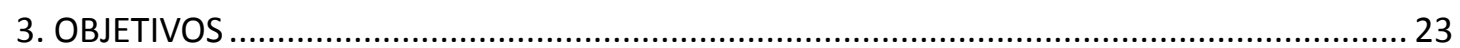

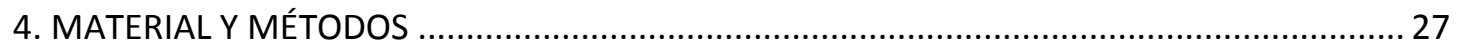

5. RELACIÓN DE ARTÍCULOS PARA LA PRESENTACIÓN DE LA TESIS DOCTORAL POR

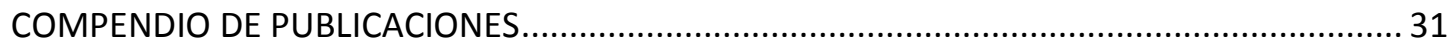

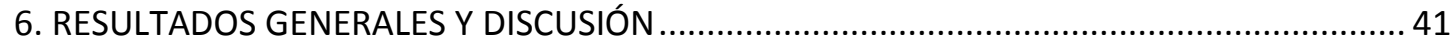

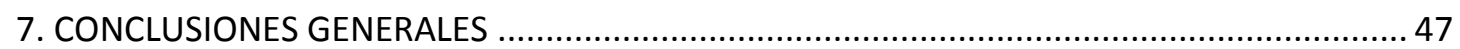

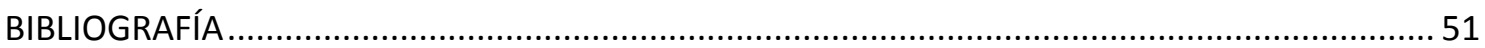




\section{INTRODUCCIÓN}

\section{MARCO CONCEPTUAL}

\subsection{LA CADENA DE VALOR AGROALIMENTARIA}

La cadena de valor agroalimentaria se define como el proceso que siguen los productos agroalimentarios desde la producción hasta el consumo. En este proceso los productos adquieren utilidades o valor de espacio, tiempo y posesión.

La metodología de la cadena de valor supone el análisis de la cadena de valor desde una perspectiva holística (Soosay et al., 2012) que supone una evaluación multidimensional de la misma y de su funcionamiento (Taylor, 2005).

El análisis cualitativo de la cadena de valor agroalimentaria supone conocer e identificar todos los agentes que intervienen en el proceso que lleva los productos agroalimentarios desde el productor hasta el consumidor.

El análisis cuantitativo de la cadena de valor supone conocer las cantidades que pasan por cada uno de los eslabones de la cadena.

Los trabajos previos han analizado la cadena de valor generalmente para un único sector. Sin embargo, Fold (2008) señala la necesidad de considerar la manera en que la cadena de valor se integra en el conjunto de cadenas de valor intrincadas que coexisten en el sistema agroalimentario.

El análisis de la cadena de valor necesita conocer las relaciones entre las diversas cadenas de valor que coexisten y su posicionamiento en un contexto institucional y local concreto (Borras et al, 2016). Por ello, los autores señalan la necesidad de, partiendo de un contexto teórico de cadena de valor, validar su funcionamiento de forma empírica en cadenas reales (Challies y Murray, 2011; Soper, 2016).

\subsection{LA SOSTENIBILIDAD DE LA CADENA DE VALOR}

La sostenibilidad de la cadena de valor agroalimentaria supone que todas las actividades desde la producción hasta el consumo agroalimentario, a la vez que cubren las necesidades de los agentes de la cadena alimentaria, protegen y conservan los recursos naturales y humanos que serán necesarios en el futuro (Erol et al., 2009; Reefke y Sundaram, 2017).

Weiss (2012) señaló que debe tratarse de una cadena de valor agroalimentaria económica, ambiental y socialmente sostenible. La cadena de valor sostenible supone desde una visión holística, que la cadena es sostenible en todos sus eslabones y relaciones (Ashby et al., 2012). 
Para alcanzar una cadena de valor sostenible socialmente el compromiso con la sociedad y responsabilidad social de todos los agentes de la cadena de valor agroalimentaria serán fundamentales (Dubey et al., 2016). Además, Erol et al. (2009) señala que una cadena de valor agroalimentaria sostenible socialmente será partícipe de las actividades de la región y apoyará a la comunidad de manera transparente y solidaria.

Dubey et al. (2016) señalaron que una cadena de valor sostenible económicamente debe garantizar la rentabilidad a todos los agentes que intervienen en la cadena a la vez de no comprometer los recursos necesarios en el futuro. Estos autores señalan que la colaboración a largo plazo entre los agentes de la cadena permitirá mejorar su actividad a la vez que mejorar el flujo de información entre los diferentes eslabones y la rentabilidad de toda la cadena. Además, una mejor colaboración y flujo de información permitirá un mejor acceso a la innovación tecnológica a todos los eslabones de la cadena y una mejor adaptación a los posibles cambios.

Para Ding et al. (2016), los gobernantes, clientes y los grupos de interés son los que pueden inducir la gestión ambientalmente sostenible de la cadena de valor agroalimentaria. Para los autores debe ser un cambio de paradigma en el que todos los agentes de la cadena de valor se involucren (Erol et al., 2009). En esta línea, Reefke y Sundaram (2017) señalaron que la regulación, el interés de los clientes, la reputación y las presiones sociales al cambio climático, limitación de los recursos, exceso de emisiones y cuestiones de salud pueden inducir la transición a una gestión ambientalmente sostenible de la cadena de valor agroalimentaria.

\subsection{SEGURIDAD ALIMENTARIA}

Según la Organización de las Naciones Unidas para la Agricultura y la Alimentación (FAO, 2019) la seguridad alimentaria se da cuando todas las personas tienen acceso físico, social y económico permanente a alimentos seguros, nutritivos y en cantidad suficiente para satisfacer sus requerimientos nutricionales y preferencias alimentarias, y así poder llevar una vida activa y saludable. En este sentido, la seguridad alimentaria incluye el acceso a los alimentos, las disponibilidad, un abastecimiento estable y continuado así como la calidad y la inocuidad de los alimentos (Gómez-Luciano et al., 2019).

El concepto incluye, en castellano, el acceso a los alimentos que comprende las funciones de comercialización, de distribución, compra-venta, transporte, etc., y la inocuidad alimentaria, que comprende la trazabilidad, gestión higiénico-sanitaria, etc. Para ello, se utilizan dos términos anglosajones diferenciados, en el primer caso 'food security' $y$ en el segundo 'food safety'. 
La inseguridad alimentaria puede estar originada por la falta de sostenibilidad de la cadena de valor. Zones et al. (2009) señalaron que factores medioambientales y humanos pueden provocar una inseguridad alimentaria grave y generalizada. Esta inseguridad origina que los aportes energéticos de la dieta sean insuficientes para cubrir las necesidades de la población y padezca malnutrición. Además de ser insuficientes, puede existir poca diversidad de alimentos (Zones et al., 2009) por lo que se dan de manera severa tanto la inseguridad alimentaria crónica como la estacional o transitoria.

A nivel familiar, la seguridad alimentaria se consigue cuando todos sus miembros tienen acceso en todo momento a alimentos suficientes para llevar una vida activa y saludable. La inseguridad alimentaria es simplemente la falta de seguridad de abastecimiento y que finalmente lleva al hambre (Balbi y Darboe, 2010). Tanto el hambre como la hambruna tienen su origen en la inseguridad alimentaria. Mientras que la inseguridad alimentaria no recoge todas las dimensiones de la pobreza, puede ser un indicador de pobreza y un importante indicador de la sostenibilidad de la cadena de valor (FAO, 2019).

Los indicadores de Seguridad Alimentaria en el Hogar (HFIAS) y de Nivel de Hambre (HHS) fueron desarrollados en el Proyecto de Asistencia Técnica Alimentaria y Nutricional (Food and Nutrition Technical Assistance Project FANTA). Los nueve indicadores que desarrollaron en el proyecto han sido validados (Household Food Insecurity Access Scale HFIAS) en diversos países (Webb et al., 2006). En 2011, a partir de su validación empírica en varios países africanos y asiáticos, los nueve ítems se redujeron a tres para obtener el Nivel de Hambre en el Hogar (FANTA, 2005). El indicador de la Diversidad de Alimentos del Hogar (HDDS) se construye a partir de un cuestionario que incluye la frecuencia de consumo de los distintos alimentos (Ballard et al., 2011; Deitchler et al., 2010).

\subsection{LA SOSTENIBILIDAD EN LA DISTRIBUCIÓN AGROALIMENTARIA}

La bibliografía señala el importante papel que tiene la distribución agroalimentaria en la sostenibilidad de la cadena de valor (Dubey et al., 2016; Trauger, 2014). Los intermediarios y las asociaciones intermedias juegan un papel primordial en la cadena de valor sostenible creando relaciones de confianza entre los eslabones y reduciendo el riesgo en el funcionamiento en la cadena, que se traducen en innovación y rentabilidad (Esfahbodi et al., 2016).

El análisis de la sostenibilidad de la distribución agroalimentaria conlleva conocer las posibles asimetrías en el flujo de la información, de productos y comunicación entre los productores y los consumidores (Soosay et al, 2012). En este sentido, Erol et al. (2009) analizaron indicadores de sostenibilidad ambiental, social y económica en el comercio detallista. 
El actual contexto globalización ha aumentado la complejidad de la distribución agroalimentaria siendo necesario aprovechar las ventajas competitivas de las diferentes regiones (Reuter et al., 2010). En este sentido Hopwood et al. (2005) señalaron que es necesario tener en cuenta la población local en una distribución sostenible y el impacto que puede tener en la sostenibilidad lo global frente a lo local. Hopwood et al. (2005) analizó la distribución internacional y la cultura nacional demostrando que el individualismo y la incertidumbre pueden influir en el desarrollo y la sostenibilidad de la cadena de valor. Por su parte Passel (2013) comparó el coste ambiental del transporte de manzanas de tres procedencias y sostuvo una mayor sostenibilidad en los sistemas locales a pesar que la globalización puede hacer crecer la economía de manera más eficiente.

Los trabajos previos muestran cómo diversos autores han desarrollado distintos modelos de distribución sostenible desde el punto vista teórico y práctico (Chin y Tat, 2015; Dam y Petkova, 2014; Ding et al., 2016). Esfahbodi et al. (2016) propone un modelo de distribución sostenible que incluye el aprovisionamiento, la distribución, el diseño y la recuperación de la inversión sostenibles. Mientras que el modelo cualitativo desarrollado por Reefke y Sundaram (2017) utilizó un estudio Delphi para identificar la planificación, ejecución, coordinación y colaboración sostenibles entre los eslabones de la cadena de distribución agroalimentaria.

\subsection{LA SOSTENIBILIDAD EN EL ESLABÓN PRODUCTOR}

La sostenibilidad en el eslabón de los productores ha sido muy analizada en la literatura, aunque siempre de manera individualizada y fuera del contexto holístico de la cadena de valor. En esta línea, se ha encontrado el análisis de la sostenibilidad de las organizaciones de los exportadores de café orgánico en Guatemala (Ortiz-Miranda y Moragues-Faus, 2015) y de uva de vinificación en Sudáfrica (Ras y Vermeulen, 2009). Avanzando en la cadena de valor también se ha medido el impacto mediante indicadores de sostenibilidad en empresas manufactureras en 55 países.

Los productores sostenibles deben adaptarse al mercado, a los estándares de calidad y a los requisitos públicos y privados de comercialización de productos agroalimentarios. En este sentido, se ha analizado cómo los productores de Ghana han diferenciado sus producciones, conseguido el sello de comercio justo para sus producciones de piña, han incorporado la responsabilidad social a su gestión, han acondicionado los productos y han preparado la expedición según los gustos de los consumidores (Fold, 2008), cómo los productores de quinoa en Bolivia se han adaptado al mercado (WalshDilley, 2013) y cómo los productores de arroz en Costa Rica se han adaptado al tratado de libre comercio (Warner, 2016). Los productores deben satisfacer los gustos de los consumidores a la vez que sortear la competencia exterior de cantidades de productos a menor precio (Borras et al., 2016). 
La literatura señala que la sostenibilidad de los productores se ve comprometida en la actualidad por la globalización (Los et al., 2015). Algunos productores se debaten con el dilema de cubrir las expectativas de los consumidores locales o satisfacer las demandas globales (Warner, 2016). La literatura muestra cómo los productores hacen pequeñas adaptaciones para no tener pérdidas debidas a la globalización de los mercados.

\subsection{LA SOSTENIBILIDAD EN EL CONSUMO}

La bibliografía señala el eslabón de consumo como decisivo en inducir con su demanda un funcionamiento sostenible en la cadena de valor (Ritzer, 2002) siendo las actitudes y comportamientos de los consumidores los más estudiados en cuanto a sostenibilidad.

Los actuales hábitos de consumo alimentario tienden a una dieta saludable, inocua (Loaharanu, 2001), diferenciada, de calidad y respetuosa con el medio ambiente (Tilman y Clark, 2014). Se observa un aumento de la demanda de productos seguros, de calidad, conveniencia, saludables, con etiquetado ecológico y respetuoso con el medio ambiente. Se considera que algunos de los factores que están condicionando las actuales tendencias globales de consumo se deben entre otras a la urbanización, el marketing agroindustrial, la liberalización de los mercados así como los problemas de obesidad, las enfermedades crónicas, como el cáncer y los problemas cardiovasculares (Kearny, 2010).

Por ello, se hace necesario conocer la percepción de los consumidores hacia el consumo sostenible y cómo ello puede determinar sus decisiones hacia cadenas de valor sostenibles. La bibliografía muestra cómo se han identificado diferentes factores que pueden influir los hábitos y la demanda alimentaria y con ello promover una cadena de valor agroalimentaria sostenible. Entre estos factores se citan:

\subsubsection{Factores psicográficos}

Los factores psicográficos se refiere a la forma en que el consumidor decide emplear su tiempo y su dinero, así como al grado en que sus valores y gustos se reflejan en sus decisiones de compra. Estos factores son decisivos en la transición hacia un consumo sostenible y hacia una cadena de valor sostenible.

Diversos autores han analizado cómo influyen en las decisiones de compra los criterios de salud, de medio ambiente y la conveniencia, así como la neofobia a productos nuevos (Pliner y Hobden, 1992) y a las nuevas tecnologías alimentarias (House, 2016). También se ha descrito cómo influyen en el consumidor las características propias del producto, así como la percepción de inocuidad, la seguridad y el contenido nutricional del producto. También se ha considerado cómo influyen en las decisiones de los consumidores, el precio, el sabor y la sostenibilidad de los productos en comparación 
con otros productos sustitutivos y menos sostenibles (Tilman y Clark, 2014; Verbeke, 2015).

\subsubsection{Fobia a nuevos alimentos}

La neofobia alimentaria se define como la reticencia a comer alimentos con los que no estamos familiarizados (Dovey et al., 2008). La literatura ha identificado que la desconfianza generalizada con los nuevos alimentos y precaución con las nuevas tecnologías alimentarias (Cox y Evans, 2008; Schnettler et al., 2013) son las principales barreras en la adopción de nuevos productos alimentarios (Damsbo-Svendsen et al., 2017).

En la bibliografía se han encontrado trece instrumentos para medir la neofobia alimentaria con diferentes resultados y procedimientos (Damsbo-Svendsen et al., 2017). Uno de los instrumentos más utilizados en la escala de neofobia alimentaria (FNS, por sus siglas en inglés Food Neophobia Scale) desarrollada por Pliner y Hobden (1992). La escala de neofobia alimentaria contiene 10 descriptores de alta fiabilidad y con bastante validez en las medidas. Sin embargo se ha discutido el número de descriptores necesarios en la escala (Preston y Colman, 2000) porque se desea el instrumento más simple que recoja la mayor información necesaria. En este sentido Ritchey et al. (2003) demostraron que entre 2 y 4 descriptores podían ser excluidos de la escala FNS, mejorando el método cuando se utiliza en varios países. Además, Damsbo-Svendsen et al. (2017) intuían que muchos descriptores no eran relevantes en muchos países. Por su parte, Van Trijp y Steenkamp (1992) propusieron la escala de búsqueda de varias tendencias, la Variety Seeking Tendency Scale (VARSEEK) en inglés, que consideraba que la terminología de "comidas exóticas" y "comidas de otros países" no sería relevante en este momento por la gran incorporación de las comidas exóticas y étnicas en la dieta actual debido a la globalización de los mercados en los últimos 25 años. Recientemente, Damsbo-Svendsen et al. (2017) recomendaron la revisión de las escalas de neofobia y aconsejaron utilizar aquella que fuera relevante en cada contexto de análisis.

\section{MARCO CONTEXTUAL}

No se han encontrado trabajos previos que traten la sostenibilidad de la cadena de valor agroalimentaria en la República Dominicana. Tan sólo se ha encontrado un informe de las Naciones Unidas con recomendaciones sobre la huella de carbono de los productos agroalimentarios que son exportados desde la República Dominicana (Frohman et al., 2012). Por su parte, la oficina de la Primera Dama de la República Dominicana ha editado una guía para promover el consumo de frutas y hortalizas en el país (SESPAS, 2009). En el eslabón de la producción se ha encontrado la mayor contribución de trabajos orientados a la sostenibilidad del sector. El Ministerio de Agricultura dominicano ha desarrollado un análisis cuantitativo de los canales de 
distribución que siguen los principales productos agroalimentarios dominicanos (IICA, 2009) identificando los intermediarios que intervienen en el canal, las cantidades que se transmiten y las relaciones entre los agentes de la cadena. Sin embargo, en ninguno de estos trabajos previos se ha considerado los mercados centrales ni tampoco las implicaciones que tiene en la cadena de valor la globalización.

\subsection{DISTRIBUCIÓN SOSTENIBLE}

Los autores señalan la necesidad de analizar la sostenibilidad de la distribución agroalimentaria especialmente en los países en desarrollo por la falta de trabajos empíricos así como por el mal funcionamiento en muchas ocasiones de la cadena en este contexto (Erol et al., 2009; Ras y Vermeulen, 2009).

Para Esfahbodi et al. (2016) una cadena de valor agroalimentaria sostenible en países en desarrollo debe por una parte, cumplir las expectativas de los operadores locales a la vez que considerar los mercados globales actuales. En este sentido, el mercado es un buen ejemplo "glocal" en el que los intereses locales y globales coexisten.

Especial atención reclaman los autores a la gestión ambientalmente sostenible de la cadena de suministro en los países en desarrollo por la ausencia de recursos ecológicos, tecnologías limpias y formación en la gestión respetuosa ambientalmente de estas cadenas.

El pilar de la distribución socialmente sostenible implica que la distribución sirve para llevar el producto desde el origen hasta el consumo (Esfahbodi et al., 2016; Soosay et al., 2012) según los gustos y necesidades de los consumidores. En la actualidad, los consumidores demandan de manera creciente productos seguros y saludables (Reefke y Sundaram, 2017) que provengan de un comercio justo (Ras y Vermeulen, 2009) por lo que la equidad en el funcionamiento de la cadena de distribución es una exigencia creciente para la sostenibilidad (Chin y Tat, 2015). Esta prioridad social requiere un flujo de bienes, servicios e información continua entre los eslabones de la cadena de valor agroalimentaria (Dam y Petkova, 2014; Dubey et al., 2016). Para Dubey et al. (2016), la cadena de valor agroalimentaria sostenible socialmente deberá tener muy en cuenta las condiciones laborales, salud y bienestar de los trabajadores de la cadena. Para Rimmington et al. (2006) la ética y la responsabilidad social de los agentes de la cadena serán fundamentales para conseguir una cadena de valor sostenible socialmente en países en desarrollo.

El pilar de sostenibilidad económica supone que la cadena de valor es rentable para todos los agentes de la cadena pero sin comprometer los recursos que serán necesarios en el futuro. La literatura muestra que la distribución agroalimentaria sostenible económicamente requiere de habilidades de gestión, organización, previsión comercial y liderazgo (Ras y Vermeulen, 2009), así como habilidades 
operativas de administración, financiación y logística (Reefke y Sundaram, 2017). Además, hay que considerar las situaciones cambiantes en las condiciones económicas, las preferencias de los consumidores, la estructura de la producción, la logística y la distribución. Por ello, la literatura indica que la distribución sostenible económicamente debe incluir la capacidad de innovar y diversificar (Dubey et al., 2016). Finalmente, los autores señalan que la distribución económicamente sostenible debe contar con una coordinación y colaboración a largo plazo entre los eslabones de la cadena (Ding et al., 2016). Esta colaboración se traducirá en una mejor comercialización de los productos y asegurará el acceso a la innovación tecnológica a todos los eslabones de la cadena. Además, aumentará el flujo de información técnica entre los eslabones de la cadena que les permitirá una mejor adaptación a los cambios (Reefke y Sundaram, 2017).

El pilar de la sostenibilidad ambiental de la cadena de suministro es el más analizado en la literatura. El manejo sostenible de la cadena de suministro dependerá de las preferencias de los clientes, la tecnología disponible y la estructura de producción y consumo (Ding et al., 2016). Esfahbodi et al. (2016) señala que la gestión de la distribución ambientalmente sostenible incluye, el aprovisionamiento sostenible, el ecodiseño, la transformación sostenible, almacenamiento y logística, re-utilización y reciclaje, (Passel, 2013; Reefke y Sundaram, 2017) además de la eliminación de residuos (Zhu et al., 2008). Reefke y Sundaram (2017) proponen el control de las emisiones de efecto invernadero a lo largo de la cadena de suministro. Además, se necesita una conciencia ambiental por parte de los agentes de la cadena (Reefke y Sundaram, 2017) y un compromiso empresarial (Dubey et al., 2016) de todos los grupos de interés de la cadena de distribución.

\subsection{PRODUCTORES SOSTENIBLES}

La sostenibilidad de los productores de los países en desarrollo requiere una especial atención por la complejidad intrínseca de las cadenas locales, la incertidumbre del valor que añaden los innumerables intermediarios presentes, la falta de cooperativismo y asociacionismo eficientes, la presencia de barreras para el acceso directo a la cadena de valor y la baja percepción de calidad y valor que tienen los consumidores de los productos locales (Pegler, 2015). A esta situación se añade el contexto de globalización de los mercados que ha producido cambios instituciones, sociales y económicos en los productores locales en los países en desarrollo (Clark e Inwood, 2012; Murmis y Murmis, 2006).

Muchos trabajos muestran las amenazas que la globalización puede provocar en los productores locales en países en desarrollo (Fold, 2008; Rutherford et al., 2016). Sin embargo, otros autores señalan que los mercados actuales ofrecen una oportunidad a los agricultores de los países en desarrollo para eliminar intermediarios con prácticas 
tradicionales abusivas y acceder a mercados con mayor valor añadido. El acceso a mercados de mayor valor ha supuesto en algunas regiones la adaptación de los productores a estos mercados. Así por ejemplo, Leguizamon (2016) muestra cómo los productores de soja de Argentina se reorganizaron, los productores de tabaco de Malawi adaptaron su producción al mercado internacional (Prowse y Moyer-Lee, 2014) y los productores de frambuesa de Chile cambiaron su modelo de negocio (Challies y Murray, 2011) para aprovechar las oportunidades de negocio que les ofrecía el mercado global.

Esta adaptación a los mercados globales puede conllevar un alto grado de tensión y stress para los productores locales de países en desarrollo (Pegler, 2015). Se necesita acompañar a los productores en este proceso y evaluar el impacto de su adaptación (Scoones, 2009) ya que pueden correr el riesgo de quedar fuera de la cadena de valor. Las instituciones, los organismos gubernamentales y el resto de la sociedad deberán acompañar a los productores en este proceso. Se hace necesario conocer la posible vulnerabilidad en los diferentes sectores (Warner, 2016).

\subsection{CONSUMO SOSTENIBLE PARA UNA CADENA DE VALOR SOSTENIBLE}

La presión ambiental generada por la producción ganadera y su consumo, especialmente de carne roja y carne procesada, así como los problemas de salud que su consumo generan, especialmente cardiovasculares, sugieren una reducción y/o sustitución de la carne en la dieta para alcanzar una alimentación sostenible (De Boer et al., 2014; Sabaté y Soret, 2014; Schösler et al., 2012; Tilman y Clark, 2014). La sustitución de la carne en la dieta, bien por carne producida de una manera más sostenible (De Boer et al., 2014) o bien por proteínas alternativas a la carne (Tilman y Clark, 2014) requiere de mecanismos de producción, distribución y promoción que hagan posible la generalización de dietas más sostenibles. En el futuro se prevé que serán necesarias grandes cantidades de proteínas de calidad saludables y respetuosas con el medio ambiente (Gerber et al., 2013).

La reducción y la sustitución de la carne en la dieta por proteínas alternativas más sostenibles ambientalmente y saludables es un reto mundial actual (De Boer et al., 2014; Tilman y Clark, 2014). Si las tendencias de consumo no varían, para 2050, la producción ganadera y la erosión del terreno serían las principales causas de las emisiones de efecto invernadero (Gerber et al., 2013; Tilman y Clark, 2014). Además, la dieta actual es la principal causante de la diabetes tipo II, de problemas coronarios y otras enfermedades. El consumo generalizado de proteínas alimentarias alternativas a la carne podría reducir las emisiones de gases de efecto invernadero debidos a la producción agraria, prevenir la erosión, la desaparición de especies en peligro de extinción y puede ayudar a prevenir las enfermedades crónicas (Kearney, 2010; Tilman y Clark, 2014). 
Por ello, la reducción y sustitución de la carne en la dieta por razones ambientales y de salud está siendo analizado actualmente como una respuesta de los consumidores concienciados con un consumo responsable y sostenible (De Boer et al., 2014; Sabaté y Soret, 2014). Sin embargo no se conoce el grado de aceptación de estas dietas en la sociedad a pesar que están irrumpiendo con fuerza en los consumidores de algunos países bajo diferentes denominaciones como flexitarianismo (Raphaely y Marinova, 2014), semi-vegetariano (Clarys et al., 2014), veganismo (Hayley et al., 2015) u omnívoro consciente (Rothgerber, 2015). Sin embargo aún se hace necesario conocer la aceptación y disposición a comprar de los consumidores de este consumo sostenible.

En este contexto, se están desarrollando e investigando diferentes proteínas alternativas a la carne.

\subsubsection{Sustitutivos de origen vegetal}

La mayoría provienen de proteínas de origen vegetal (De Boer y Aiking, 2011) y/o micoproteínas que constituyen un mercado bien desarrollado y conocido.

En comparación con la carne tradicional, las proteínas de origen vegetal son menos perjudiciales para el medio ambiente (De Boer y Aiking, 2011), más saludables (Sabaté y Soret, 2014) y previenen el sufrimiento animal (Foer, 2010).

La literatura señala distintos factores que determinan una dieta rica en proteínas vegetales, el género, la edad, la educación (Graça et al., 2015), el saber preparar los vegetales y estar familiarizado con las verduras (Schosler et al., 2012), estar siguiendo una dieta de control de peso (De Boer et al., 2014; Herman y Polivy, 2008), por salud (Gerber et al., 2013; Sadler, 2004; Tilman y Clark, 2014), por conciencia ambiental (De Boer et al., 2014; Sabaté y Soret, 2014; Tilman y Clark, 2014), por cuestiones éticas (De Boer et al., 2007), por concienciación con el bienestar animal (Bryant y Barnett, 2018), por naturismo (Sadler, 2004) o por influencia del entorno del consumidor (Schosler et al., 2012).

\subsubsection{Sustitutivos de base tecnológica}

Por otra parte, la carne in vitro o carne cultivada proviene del cultivo de las células musculares extraídas previamente de animales y ya ha sido desarrollada y lanzada al mercado en diferentes países (Keefe, 2018; Post, 2014).

Los principales factores que se han encontrado para que los consumidores acepten la carne cultivada dependen de la influencia en los consumidores de la información volcada por los medios de comunicación (Goodwin y Shoulders, 2013), de la confianza del consumidor en la ciencia (Verbeke et al., 2015) y del precio y las características comparadas con la carne tradicional (Verbeke et al., 2015). 


\subsubsection{Sustitutivos basados en proteínas de insectos}

Se han considerado los insectos como proteínas alternativas a la carne (Lombardi et al., 2018; Verbeke, 2015) que fueron regulados en 2018 como producto alimentario por la Unión Europea (Lombardi et al., 2018) y están siendo altamente promocionados en los países occidentales. Los insectos están ganando popularidad como fuente alternativa de proteínas a la carne (Van Huis, 2013; Verbeke, 2015) y es habitual encontrarlos en aplicaciones etnoculinarias, concursos y programas televisivos, promociones gubernamentales $\mathrm{y}$ en demostraciones de expertos en salud y chefs (DeFoliart, 2010). Además, son habituales los debates sobre los insectos como alimento, la sostenibilidad ambiental y como fuente alimentaria saludable (House, 2016; Tilman y Clark, 2014) en las redes sociales, blogs culinarios, etc. (Verkerk et al., 2007).

Los insectos han sido un producto consumido principal y tradicionalmente en las áreas rurales (Hartmann et al., 2015) y en la actualidad se consumen en las zonas urbanas de clase alta que los consideran un producto gourmet o de exclusividad (Yen, 2009). Sin embargo, el consumo de insectos no está generalizado y se necesita dilucidar las razones que llevan a los consumidores a aceptar el consumo de insectos (House, 2016).

Sin embargo, aún existen muchos tabús entre los consumidores para comer insectos (Yen, 2009) y su aceptación o rechazo no son casuales o aleatorios, sin embargo se desconocen a pesar que se consuman por tradición y comúnmente en diversas culturas (Caparros Megido et al., 2014). Se cree que las razones de tabú a ciertos insectos se deben a tradiciones y creencias que hacen que determinadas especies se consuman y otras no (Yen, 2009). House (2016) señaló que pudiera depender de las especies de insectos disponibles en cada zona aunque no encontró relación directa del por qué determinadas sociedades utilizan más o menos los insectos como alimento. Algunos autores han indicado que el rechazo a los insectos en general pudiera deberse a que son percibidos por los humanos como transmisores de enfermedades, plagas en los cultivos (Van Huis, 2013), depredadores en los silos (House, 2016) y contaminantes de los alimentos (Vriesekoop y Shaw, 2010) y con consecuencias intestinales negativas (Caparros Megido et al., 2014). Verbeke (2015) analizó los factores determinantes del consumo de insectos entre los consumidores occidentales y encontró: el género, la edad, familiaridad, conveniencia, medio ambiente, intenciones futuras de consumo y la fobia a nuevos alimentos. Para House (2016) se debía a factores psicológicos como la curiosidad, influencia social y la publicidad de estos productos.

Diversos autores han analizado la aceptación de los insectos como alimento en países desarrollados como Bélgica (Caparros Megido et al., 2014; Schouteten et al., 2016; Vanhonacker et al., 2013; Verbeke, 2015), Dinamarca (Verneau et al., 2016), Alemania (Hartmann et al., 2015), Italia (Lombardi et al., 2018; Sidali et al., 2019; Verneau et al., 
2016), los Países Bajos (De Boer et al., 2014; House, 2016; Schosler et al., 2012; Tan et al., 2016), Suiza (Gmuer et al., 2016), Estados Unidos (Ruby et al., 2015), Canadá (Looy y Wood, 2006), Australia (Yen, 2009) o China (Hartmann et al., 2015). Sin embargo, poco se ha investigado sobre la aceptación de los insectos como alimento en los países en desarrollo a pesar que algunos autores han señalado que podrían ser una fuente de nutrientes (Yen, 2009) en estos países para cubrir las necesidades alimentarias que padecen (Caparros Megido et al., 2014; Testa et al., 2017). Ruby et al. (2015) clasificaron el mundo en países desarrollados consumidores y no consumidores de insectos y países en desarrollo que consumen y no consumen insectos y señalaron que los países que más se podrían beneficiar de la adopción de los insectos como alimentos serían los países desarrollados que los rechazan, aproximadamente unos mil millones de habitantes del mundo, y los habitantes de países en desarrollo que no los consumen, unos 4 mil millones que son el mayor grupo y más crítico del mundo. La investigación se debe centrar en estos dos grupos de interés (Tilman y Clark, 2014) pero además las diferencias en la adopción de los insectos como alimento hacen necesario una mayor investigación empírica que permita conocer los factores que afectan la aceptación o rechazo de los insectos como alimento (House, 2016).

\subsubsection{La posible sustitución de la carne en la dieta y desarrollo económico}

La mayoría de los autores han analizado la sustitución de la carne por hábitos de consumo sostenible en países desarrollados (De Boer et al., 2014; Graça et al., 2015; Sabaté y Soret, 2014; Schosler et al., 2012) y pocas investigaciones se han llevado a cabo en países en desarrollo donde el crecimiento económico y de la urbanización llevan aparejadas un aumento del consumo de carne (Tilman y Clark, 2014). Sabaté y Soret (2014) señalan que el consumo de carne ha aumentado un 300\% en los países en desarrollo desde los años 60 mientras que en el resto del mundo ha incrementado sólo un $62 \%$ en este periodo. En este sentido, no se ha encontrado ningún trabajo previo en la República Dominicana.

Tilman y Clark (2014) demostraron que aumentos en la renta se relacionaban con un aumento de la demanda diaria de proteínas, carne y "calorías vacías" procedentes de las grasas, el azúcar refinado, el alcohol y los aceites. Estas tendencias de consumo se asocian a la producción industrializada, el libre comercio, la multinacionales alimentarias, el crecimiento de la distribución alimentaria globalizada y las actitudes y comportamientos de los consumidores (Tilman y Clark, 2014).

La investigación ha analizado como indicador de la posible demanda del eslabón consumidor de una cadena de valor sostenible, el grado de aceptación y disposición a comprar sustitutivos a la carne (Goodwin y Shoulders, 2013; Post, 2014; Schosler et al., 2012; Verbeke, 2015) en la República Dominicana. Además, la investigación ha comparado el grado de aceptación y disposición a comprar las diferentes alternativas a la carne en el contexto del grado de desarrollo económico de los diferentes países. 
Wansink (2002) demostró que la sustitución de la carne por proteínas alternativas dependía de la disponibilidad de alternativas a la carne, el sabor, la familiaridad de los consumidores, su apariencia y el grado de cumplimiento de las características esperadas. La aceptación de los atributos de las alternativas a la carne dependían de su cualidad sensorial, seguridad, precio y disponibilidad (Verbeke et al., 2015).

\subsubsection{El consumo de carne en la República Dominicana}

Tilman y Clark (2014) indicaron que en los países con mayor grado crecimiento económico y de urbanización, el consumo de carne está aumentando mientras que la la concienciación ambiental y la salud está originando un estancamiento global o disminución de las cantidades de carne en la dieta (FAO, 2019). En este sentido y como ejemplo se muestra la evolución del consumo de carne en la República Dominicana (país situado en el grupo cuarto de desarrollo económico según la clasificación de 100 países según grado de desarrollo económico realizada por Tilman y Clark (2014)) y el Reino Unido, situado en el primer grupo de los quince países con mayor nivel económico. Tilman y Clark (2014) demostraron que los 15 países del grupo de mayor desarrollo económico tenían una demanda de proteínas de carne de rumiantes, mariscos, pollo y cerdo un $750 \%$ mayor que los países del grupo de menor desarrollo económico. En esta línea Sabaté y Sorret (2014) indicaron que mientras en los países en desarrollo el consumo de carne había aumentado un $300 \%$ desde los años 60 , en el resto del mundo el crecimiento del consumo en este periodo había sido de un $62 \%$. Algunos autores como Austin (2010) achacan esta tendencia a la mayor disponibilidad y fácil acceso a la carne en los países en desarrollo por ser la ganadería una actividad preponderante en estos países y por el alto grado de autoconsumo.

Tabla 1. Consumo de carne por persona y año en un país del grupo 1 y un país del grupo 4 de desarrollo económico, incremento del consumo desde 1961 y 2013. Fuente: Naciones Unidas (FAO, 2019)

\begin{tabular}{|c|c|c|c|c|c|c|c|}
\hline \multirow{2}{*}{ Country } & \multicolumn{6}{|c|}{ Año } & \multirow{2}{*}{$\begin{array}{l}\text { Incremento } \\
1961-2013\end{array}$} \\
\hline & 1961 & 1970 & 1980 & 1990 & 2000 & 2013 & \\
\hline Reino Unido & 69,24 & 72,64 & 70,64 & 72,51 & 77,06 & 81,49 & 1,17 \\
\hline Republica Dominicana & 15,34 & 15,29 & 24,36 & 30,44 & 40,00 & 47,20 & 3,08 \\
\hline
\end{tabular}

La producción de carne sigue la tendencia de la demanda. La producción de carne en el Caribe se ha triplicado entre 1960 y 2014, de 395.556 toneladas a 1,21 miles de toneladas, mientras que en Europa tan solo se ha duplicado en el mismo periodo (FAO, 2019). 


\section{OBJETIVOS}

Esta tesis tuvo por objetivo analizar la sostenibilidad de la cadena de valor agroalimentaria y su evaluación en la cadena de valor de la República Dominicana. Para ello, partiendo de la metodología de cadena de valor, que consiste en analizar los eslabones de la cadena de valor agroalimentaria desde el productor hasta el consumidor (Soosay et al., 2012), se realizaron ajustes o aumentos a esta metodología en base a trabajos previos. Este enfoque de metodología de la cadena de valor aumentada consideró una perspectiva holística (Soosay et al., 2012) en el análisis de la cadena de valor, que tuvo por objeto una evaluación multidimensional de la misma y de su funcionamiento (Taylor, 2005). Este aumento se sustenta en las premisas de Fold (2008) que señala la necesidad de considerar la manera en que la cadena de valor se integra en el conjunto de cadenas de valor intrincadas que coexisten en el sistema agroalimentario. En este sentido, la investigación se propuso aumentar la metodología de cadena de valor, desde una perspectiva holística, con cuatro objetivos: i) analizar las relaciones intrincadas entre los diferentes sectores, en vez de uno a uno Fold (2008), ii) llevar a cabo un análisis cualitativo y cuantitativo conjuntamente, en vez de cada uno por separado(Soosay et al., 2012), iii) conocer las relaciones entre las diversas cadenas de valor que coexisten y su posicionamiento en un contexto institucional y local concreto (Borras et al, 2016) y iv) validar su funcionamiento de forma empírica en cadenas reales partiendo de un contexto teórico de cadena de valor, (Challies y Murray, 2011; Soper, 2016). La cadena de valor sostenible supone así desde una visión holística, que la cadena es sostenible en todos sus eslabones y relaciones (Ashby et al., 2012).

El objetivo de evaluación de la cadena de valor en la República Dominicana se apoya en la necesidad de sostenibilidad de la distribución agroalimentaria especialmente en los países en desarrollo por la falta de trabajos empíricos así como por el mal funcionamiento en muchas ocasiones de la cadena en este contexto (Erol et al., 2009; Ras y Vermeulen, 2009). La existencia en el país de tan sólo de un informe de las Naciones Unidas con recomendaciones sobre la huella de carbono de los productos agroalimentarios que son exportados (Frohman et al., 2012), una guía para promover el consumo de frutas y hortalizas de la oficina de la Primera Dama (SESPAS, 2009) y un análisis cuantitativo de los canales de distribución que siguen los principales productos agroalimentarios dominicanos (IICA, 2009) reafirma el objetivo de analizar la cadena de valor agroalimentaria dominicana.

La investigación y el documento de tesis doctoral han sido estructurado en referencia a los tres eslabones más significativos de la cadena de valor agroalimentaria con el objeto de simplificar y facilitar la presentación de los resultados, como son: i) la producción, ii) la distribución y iii) el consumo. 
En cada uno de los eslabones, el trabajo tuvo por objeto analizar o dar luz a los posibles factores y circunstancias que pueden amenazar el desarrollo de una cadena de valor sostenible.

1. En el eslabón de la distribución el objetivo fue analizar la sostenibilidad de la distribución agroalimentaria que conlleva a conocer las posibles asimetrías en el flujo de la información, de productos y comunicación entre los productores y los consumidores (Soosay et al, 2012). A partir de los trabajos previos que muestran cómo diversos autores han desarrollado distintos modelos de distribución sostenible desde el punto vista teórico y práctico (Chin y Tat, 2015; Dam y Petkova, 2014; Ding et al., 2016), la investigación tuvo por objeto combinar el modelo de distribución sostenible que propone Esfahbodi et al. (2016) que incluye el aprovisionamiento, la distribución, el diseño y la recuperación de la inversión sostenibles con el modelo cualitativo desarrollado por Reefke y Sundaram (2017) que utilizó un estudio Delphi para identificar la planificación, ejecución, coordinación y colaboración sostenibles entre los eslabones de la cadena de distribución agroalimentaria.

Para ello se propusieron los siguientes objetivos específicos:

1.1. Identificar los indicadores de sostenibilidad de la cadena de valor agroalimentaria (art. 1).

1.2. Desarrollar un modelo de distribución glocal sostenible (art. 1 y 2).

1.3. Proporcionar un marco teórico y empírico de manejo sostenible de la cadena de distribución agroalimentaria en la República Dominicana (art. 1).

1.4. Demostrar si el mercado central puede contribuir a la sostenibilidad social de la cadena de valor mediante la mejora del flujo de información y seguridad de la cadena de valor agroalimentaria (art. 1).

1.5. Confirmar si el mercado central puede contribuir al desarrollo de la sostenibilidad económica de la cadena de valor mediante la integración de los productores locales y la eliminación de intermediarios (art. 1).

1.6. Analizar si el mercado central puede contribuir a la sostenibilidad ambiental de la cadena de valor agroalimentaria mediante la certificación ambiental y la reducción de la distancia recorrida por los productos (art. 1).

2. En el sector de la producción, el objetivo fue analizar las relaciones entre las diversas cadenas de valor que coexisten y su posicionamiento en un contexto institucional y local concreto (Borras et al, 2016). En el sector de la producción los objetivos han tenido en cuenta que la sostenibilidad de los productores de los países en desarrollo requiere una especial atención por la complejidad intrínseca de las cadenas locales, la incertidumbre del valor que añaden los innumerables intermediarios presentes, la falta de cooperativismo y asociacionismo eficientes, la presencia de barreras para el acceso directo a la 
cadena de valor y la baja percepción de calidad y valor que tienen los consumidores de los productos locales (Pegler, 2015). A esta situación se añade el contexto de globalización de los mercados que ha producido cambios instituciones, sociales y económicos en los productores locales en los países en desarrollo (Clark e Inwood, 2012; Murmis y Murmis, 2006).

Para ello se propusieron los siguientes objetivos específicos:

2.1. Conocer el alineamiento del eslabón productor con el consumidor y la distribución (art. 1 y 2 ).

2.2. Obtener los factores que determinan que un productor acceda a cadenas de valor (art. 1 y 2 ).

2.3. Evaluar las necesidades de adaptación de la producción a cadenas de valor sostenibles (art. 1, 2 y 3).

2.4. Ordenar los sectores agrícolas según vulnerabilidad respecto a cadenas de valor sostenibles (art. 2).

2.5. Caracterizar la contribución de las asociaciones de productores a las cadenas de valor sostenibles (art. 1 y 2 ).

3. En el eslabón de consumo el objetivo fue analizar el impacto de posibles nuevas tendencias de consumo globales para el caso de la sustitución de la carne en la dieta por proteínas alternativas y analizar por perfiles los posibles adoptadores de dietas sostenibles en comparación con otros países de diferente desarrollo económico. El manejo sostenible de la cadena de suministro dependerá de las preferencias de los clientes, la tecnología disponible y la estructura de producción y consumo (Ding et al., 2016).

3.1. Determinar los factores que inducen un consumo sostenible (art. 1, 2, 3 y 4).

3.2. Identificar el perfil de los consumidores adoptadores de un consumo sostenible (art. 3).

3.3. Comparar el grado de adopción del consumo sostenible por países según el desarrollo económico (art 3 y 4 ).

3.4. Conocer entre las alternativas sustitutivas a la carne tradicional cuáles son preferidas (art. 3 y 4 ).

3.5. Hacer previsiones de la disposición a comprar alternativas a la carne en cuatro países con diferente nivel económico (art. 4).

3.6. Identificar las características que deben cumplir los productos sustitutivos para inducir la transición a dietas y una cadena de valor agroalimentaria sostenible (art. 3 y 4 ). 


\section{MATERIAL Y MÉTODOS}

\section{Eslabón distribuidor}

Con el objetivo de analizar la distribución agroalimentaria en la República Dominicana se realizaron entrevistas personales a 24 mayoristas y 30 minoristas de un total de 35 y 40 respectivamente del mercado central. Además, se entrevistó al director general y gerente del mercado central de Santo Domingo. Los datos se analizaron mediante un análisis de significación que permitió obtener las diferencias entre grupos (art. 1).

\section{Eslabón de los productores}

En el análisis de los productores se empleó una muestra de 234 agricultores de la provincia de Barahona en la República Dominicana. Los productores fueron seleccionados por las asociaciones de productores de arroz $(14,5 \%)$, batata $(14,5 \%)$, aguacate $(4,3 \%)$, café $(22,2 \%)$, guandul $(14,5 \%)$, alubias $(15,0 \%)$ y plátano orgánico $(15,0 \%)$. Eran en su mayoría hombres con edades comprendidas entre los 46 y los 60 años $(46,15 \%)$ con la educación primaria comenzada $(46,2 \%)$. Los productores cultivaban una media de $9,89( \pm 1,13)$ metros cuadrados y contaban con algún trabajador. La mayoría no tenía acceso a crédito agrícola (55.56\%) y contaban con alguna asistencia técnica (55.98\%).

Los datos fueron tratados con la herramienta informática SPSS y mediante un análisis de significación y contingencia se obtuvieron los perfiles de los productores. Un análisis multicriterio Electre I sirvió para clasificar los sectores agrícolas según criterios de vulnerabilidad y un análisis de regresión logística permitió identificar los factores determinantes en el acceso de los productores a la cadena de valor (art. 1 y 2 ).

\section{Eslabón consumidor}

Para analizar el impacto de posibles nuevas tendencias de consumo globales, en el caso de la sustitución de la carne en la dieta por proteínas alternativas y analizar los perfiles de los posibles adoptadores de dietas sostenibles en comparación con otras regiones con distinto desarrollo económico se emplearon diferentes métodos de investigación de mercados en consonancia con los objetivos propuestos.

La principal fuente de información utilizada fueron los consumidores de la República Dominicana y de países de distinto desarrollo económico según la clasificación de Tilman y Clark (2014). Del grupo A, que comprende los 15 países de mayor renta, se seleccionó el Reino Unido, del grupo B se seleccionó España y del grupo C se seleccionó Brasil. La República Dominicana pertenece al grupo $D$ de países según renta.

El principal método de recogida de datos fue la entrevista personal. En unos casos mediante cuestionario digital, en otros casos cara a cara o mediante sesiones grupales. Se realizaron en este eslabón un total de 983 entrevistas personales. 
El principal medio de recogida de datos fue el cuestionario semi-estructurado con preguntas cerradas, abiertas y de respuesta múltiple según la información que se deseara recabar. La información a recabar fue de tres tipos: i) hábitos de consumo, ii) preferencias en las decisiones de compra y iii) factores psicográficos. Además, se recogieron datos personales que sirvieron para clasificar las variables de análisis en base al perfil de los encuestados. Los instrumentos validados de recogida de información fueron las escalas de factores psicográficos y de decisión de compra revisados en los antecedentes del trabajo: escala de neofobia (FNS; Pliner y Hobden, 1992), escala tecnología alimentaria neofobia (FTNS; Cox y Evans, 2008), actitudes salud sobre los alimentos (Roininen et al., 1999), impacto del medio ambiente en las decisiones de compra (Roberts, 1996; Verbeke, 2015), e importancia de la conveniencia en las decisiones de compra (Candel, 2001) (art. 3 y 4).

El tratamiento de los datos se realizó con la herramienta SPSS y consistió en: i) un análisis de contingencia de Pearson que permitió relacionar la probabilidad de ocurrencia de las variables analizadas con el perfil de los consumidores, ii) un análisis ANOVA que sirvió para comparar las actitudes en diferentes regiones, iii) un análisis de componentes principales que sirvió para reducir las variables de las escalas y eliminar la posible multicolinealidad y iv) un análisis de regresión logística binaria que sirvió para identificar las variables determinantes en la compra de productos sustitutivos a la carne más sostenibles (art. 3 y 4 ).

Finalmente, un grupo de discusión con 11 técnicos, investigadores, agentes y sociedad civil de la República Dominicana sirvió para evaluar y debatir sobre la cadena de valor agroalimentaria de la República Dominicana en su conjunto (art. 1 y 2 ).

La tesis doctoral se compone de cuatro artículos publicados en revistas indexadas en el Journal Citation Index (JCR). En el primer artículo se encuentran los indicadores de sostenibilidad de la cadena de valor y el análisis de la sostenibilidad de la distribución agroalimentaria según los pilares de sostenibilidad ambiental, social y económica. En el segundo artículo se ha caracterizado el eslabón productor según criterios de sostenibilidad en su acceso a la cadena de valor y se han determinado los factores que determinan el acceso de los productores a cadenas de valor sostenibles. En el tercer artículo se ha obtenido el perfil de los primeros adoptadores de dietas sostenibles medido por la reducción de la carne en la dieta en la República Dominicana y en España. En el cuarto artículo se ha comparado la disposición a comprar tres alternativas a la carne en cuatro países con diferente desarrollo económico. 
Tabla 2. Resumen de métodos y materiales empleados en el análisis de la sostenibilidad de la cadena de valor agroalimentaria dominicana

\begin{tabular}{|c|c|c|c|c|}
\hline OBJETIVO & MATERIAL & MÉTODO & TRATAMIENTO DE DATOS & RESULTADO ESPERADO \\
\hline \multicolumn{5}{|c|}{ Eslabón de la distribución } \\
\hline $\begin{array}{l}\text { Conocer el } \\
\text { funcionamiento del } \\
\text { mercado central }\end{array}$ & $\begin{array}{l}\text { Gerente y director } \\
\text { de Merca Santo } \\
\text { Domingo }\end{array}$ & $\begin{array}{l}\text { Entrevistas } \\
\text { personales }\end{array}$ & Análisis descriptivo & $\begin{array}{l}\text { Conocer las medidas que } \\
\text { contribuyen a la } \\
\text { sostenibilidad de la } \\
\text { cadena de valor }\end{array}$ \\
\hline $\begin{array}{l}\text { Caracterizar el flujo } \\
\text { de bienes, } \\
\text { información y } \\
\text { servicios en el } \\
\text { eslabón mayorista }\end{array}$ & $\begin{array}{l}24 \text { mayoristas de } \\
\text { Merca Santo } \\
\text { Domingo }\end{array}$ & $\begin{array}{l}\text { Entrevistas } \\
\text { personales }\end{array}$ & $\begin{array}{l}\text { Análisis de significación } \\
\text { ANOVA }\end{array}$ & $\begin{array}{l}\text { Identificar el flujo de } \\
\text { bienes, información y } \\
\text { comunicación entre los } \\
\text { eslabones de la cadena }\end{array}$ \\
\hline $\begin{array}{l}\text { Identificar la } \\
\text { actividad de los } \\
\text { minoristas }\end{array}$ & $\begin{array}{l}30 \text { minoristas de } \\
\text { Merca Santo } \\
\text { Domingo }\end{array}$ & $\begin{array}{l}\text { Entrevistas } \\
\text { personales }\end{array}$ & $\begin{array}{l}\text { Análisis de significación } \\
\text { ANOVA }\end{array}$ & $\begin{array}{l}\text { Identificar el flujo de } \\
\text { bienes, información y } \\
\text { comunicación entre los } \\
\text { eslabones de la cadena }\end{array}$ \\
\hline $\begin{array}{l}\text { Evaluar la actuación } \\
\text { de las asociaciones } \\
\text { de productores en la } \\
\text { cadena de valor }\end{array}$ & $\begin{array}{l}18 \text { expertos de } \\
\text { asociaciones de } \\
\text { productores, } \\
\text { técnicos y sociedad } \\
\text { civil }\end{array}$ & Grupos Delphi & Análisis de frecuencia & $\begin{array}{l}\text { Analizar los factores de } \\
\text { acceso de los productores } \\
\text { a la cadena de valor y que } \\
\text { evalúan su sostenibilidad }\end{array}$ \\
\hline \multicolumn{5}{|c|}{ Eslabón de la producción } \\
\hline $\begin{array}{l}\text { Conocer los } \\
\text { problemas del } \\
\text { eslabón de la } \\
\text { producción hacia } \\
\text { cadenas de valor } \\
\text { sostenibles }\end{array}$ & $\begin{array}{l}234 \text { productores de } \\
\text { Barahona }\end{array}$ & $\begin{array}{l}\text { Entrevistas } \\
\text { personales }\end{array}$ & $\begin{array}{l}\text { Significación Chi-cuadrado } \\
\chi^{2} \\
\text { Regresión logística } \\
\text { Análisis multicriterio } \\
\text { Electre I }\end{array}$ & $\begin{array}{l}\text { Factores determinantes } \\
\text { para el acceso a cadenas } \\
\text { de valor añadido y } \\
\text { ordenación de los sectores } \\
\text { agrícolas por } \\
\text { vulnerabilidad }\end{array}$ \\
\hline $\begin{array}{l}\text { Evaluar el grado de } \\
\text { conexión entre la } \\
\text { demanda delos } \\
\text { consumidores, la } \\
\text { producción y la } \\
\text { distribución }\end{array}$ & $\begin{array}{l}402 \text { consumidores } \\
\text { de Santo Domingo }\end{array}$ & $\begin{array}{l}\text { Entrevistas } \\
\text { personales }\end{array}$ & $\begin{array}{l}\text { Análisis de contingencia } \\
\text { Significación Chi-cuadrado } \\
\chi^{2}\end{array}$ & $\begin{array}{l}\text { Percepción de los } \\
\text { consumidores de los } \\
\text { productos, mercados y } \\
\text { distribución de los } \\
\text { productos } \\
\text { agroalimentarios locales }\end{array}$ \\
\hline \multicolumn{5}{|l|}{ Eslabón consumidor } \\
\hline $\begin{array}{l}\text { Conocer el grado de } \\
\text { sustitución hacia un } \\
\text { consumo sostenible }\end{array}$ & $\begin{array}{l}983 \text { consumidores } \\
\text { de } 4 \text { países }\end{array}$ & $\begin{array}{l}\text { Entrevistas } \\
\text { personales digitales } \\
\text { y cara a cara }\end{array}$ & $\begin{array}{l}\text { ANOVA } \\
\text { Correlación De Pearson } \\
\text { ACP } \\
\text { Regresion Logística Binaria }\end{array}$ & $\begin{array}{l}\text { Disposición a comprar } 3 \\
\text { alternativas a la carne }\end{array}$ \\
\hline $\begin{array}{l}\text { Analizar el perfil de } \\
\text { los consumidores } \\
\text { sostenibles }\end{array}$ & $\begin{array}{l}401 \text { consumidores } \\
\text { de España y } \\
\text { República } \\
\text { Dominicana }\end{array}$ & $\begin{array}{l}\text { Entrevistas } \\
\text { personales cara a } \\
\text { cara }\end{array}$ & $\begin{array}{l}\text { Correlación De Pearson } \\
\text { Caracterización de } \\
\text { consumidores }\end{array}$ & $\begin{array}{l}\text { Perfil de consumidores de } \\
4 \text { alternativas a la carne }\end{array}$ \\
\hline \multicolumn{5}{|c|}{ Visión holística de la cadena de valor agroalimentaria } \\
\hline $\begin{array}{l}\text { Evaluar } \\
\text { sostenibilidad de la } \\
\text { cadena de valor } \\
\text { agroalimentaria }\end{array}$ & $\begin{array}{l}11 \text { técnicos, } \\
\text { investigadores, } \\
\text { ciudadanos y } \\
\text { agentes de la cadena }\end{array}$ & $\begin{array}{l}\text { Grupo de debate } \\
\text { guiado }\end{array}$ & Análisis descriptivo & $\begin{array}{l}\text { Recomendaciones para la } \\
\text { sostenibilidad de la } \\
\text { cadena de valora } \\
\text { agroalimentaria }\end{array}$ \\
\hline
\end{tabular}




\section{RELACIÓN DE ARTÍCULOS PARA LA PRESENTACIÓN DE LA TESIS DOCTORAL POR COMPENDIO DE PUBLICACIONES}

Art. 4.1 de la Normativa para la presentación y defensa de la tesis doctoral en la UVa

Autor D. Cristino Alberto Gómez Luciano

\section{Artículo 1:}

Gómez-Luciano, C.A.; Rondón, F.R.; González-Andrés, F.; Urbano, B. 2018. Sustainable Supply Chain Management: Contributions of Supplies Markets. Journal of Cleaner Production, 184, pp. 311-320. DOI: 10.1016/j.jclepro.2018.02.233

Base de indexación JCR

Índice de impacto 6,395 (Año 2018) (Q1)

\section{Artículo 2:}

Gómez-Luciano, C.; de Aguiar, L.; Vriesekoop, F. and Urbano, B. 2019. Consumers' willingness to purchase three alternative proteins to meat in United Kingdom, Spain, Brazil and the Dominican Republic. Food Quality and Preference. DOI: 10.1016/j.foodqual.2019.103732

Base de indexación JCR

Índice de impacto 3,684 (Año 2018) (Q1)

\section{Artículo 3:}

Gómez-Luciano, C.; Vriesekoop, F. and Urbano, B., 2019. Towards Food Security of Alternative Dietary Proteins: a Comparison between Spain and the Dominican Republic. Amfiteatru Economic, 21(51), pp. 393-407. DOI: 10.24818/EA/2019/51/393

Base de indexación JCR

Índice de impacto 1,238 (Año 2018) (Q2)

\section{Artículo 4:}

Gómez-Luciano, C.; de Koning, W.; Vriesekoop, F. and Urbano, B., 2019. A model of agricultural sustainable added value chain: The case of the Dominican Republic value chain. Revista de la Facultad de Ciencias Agrarias, 51, pp. 111-124. Publicado en junio de 2019.

Base de indexación JCR

Índice de impacto 1,158 (Año 2018) (Q2) 


\section{Artículo 1:}

Gómez-Luciano, C.A.; Rondón, F.R.; González-Andrés, F. and Urbano, B. 2018.

Sustainable Supply Chain Management: Contributions of Supplies Markets.

Journal of Cleaner Production, 184, pp. 311-320.

DOI: 10.1016/j.jclepro.2018.02.233. Publicado el 20 de mayo de 2018.

Base de indexación JCR

Índice de impacto 6,395 (Año 2018) (Q1)
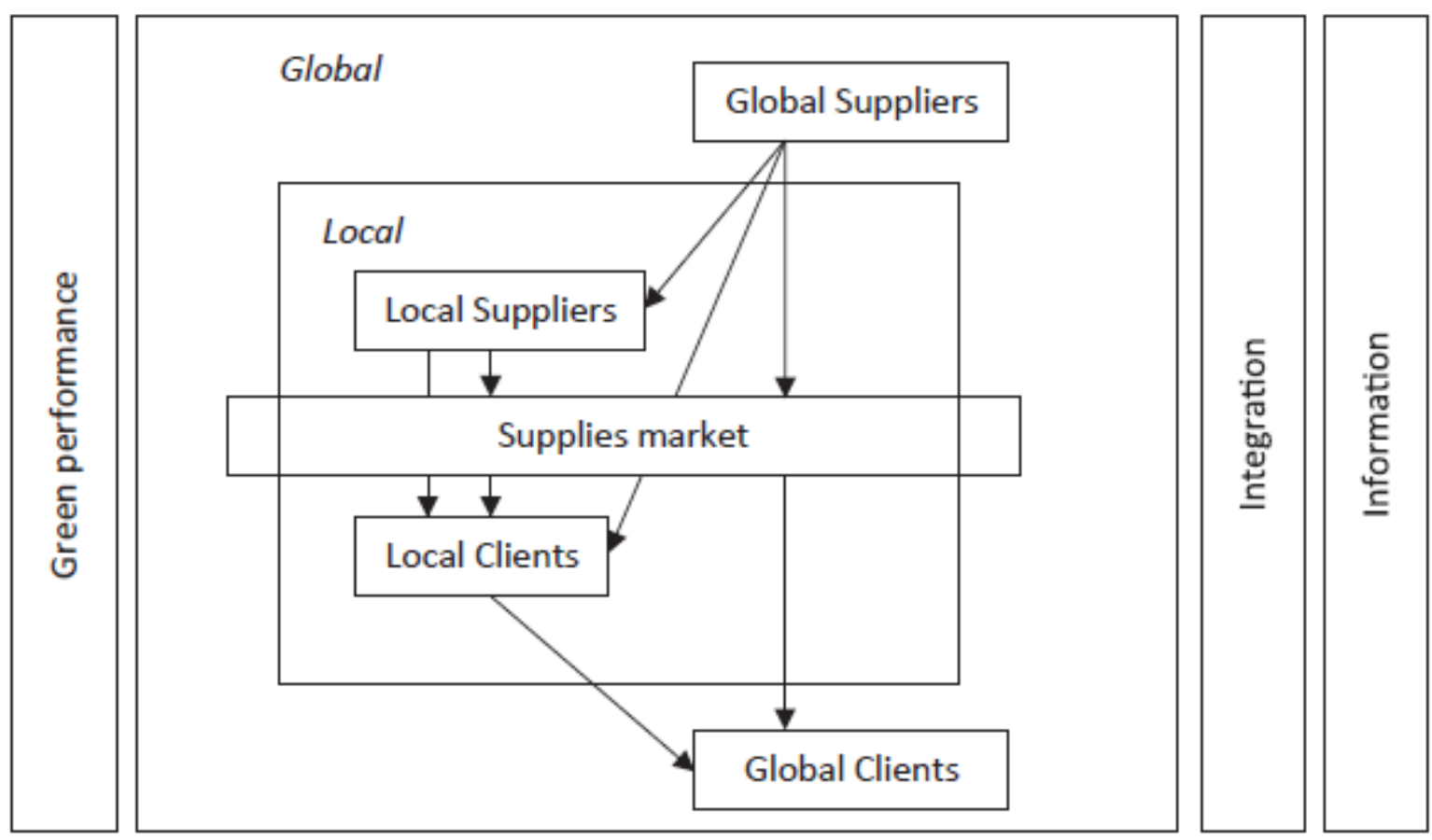


\section{Artículo 2:}

Gómez-Luciano, C.; de Koning, W.; Vriesekoop, F. and Urbano, B. 2019. A model of agricultural sustainable added value chain: The case of the Dominican Republic value chain. Revista de la Facultad de Ciencias Agrarias, 51, pp. 111-124.

Publicado en junio de 2019.

Base de indexación JCR

Índice de impacto 1,158 (Año 2018) (Q2)

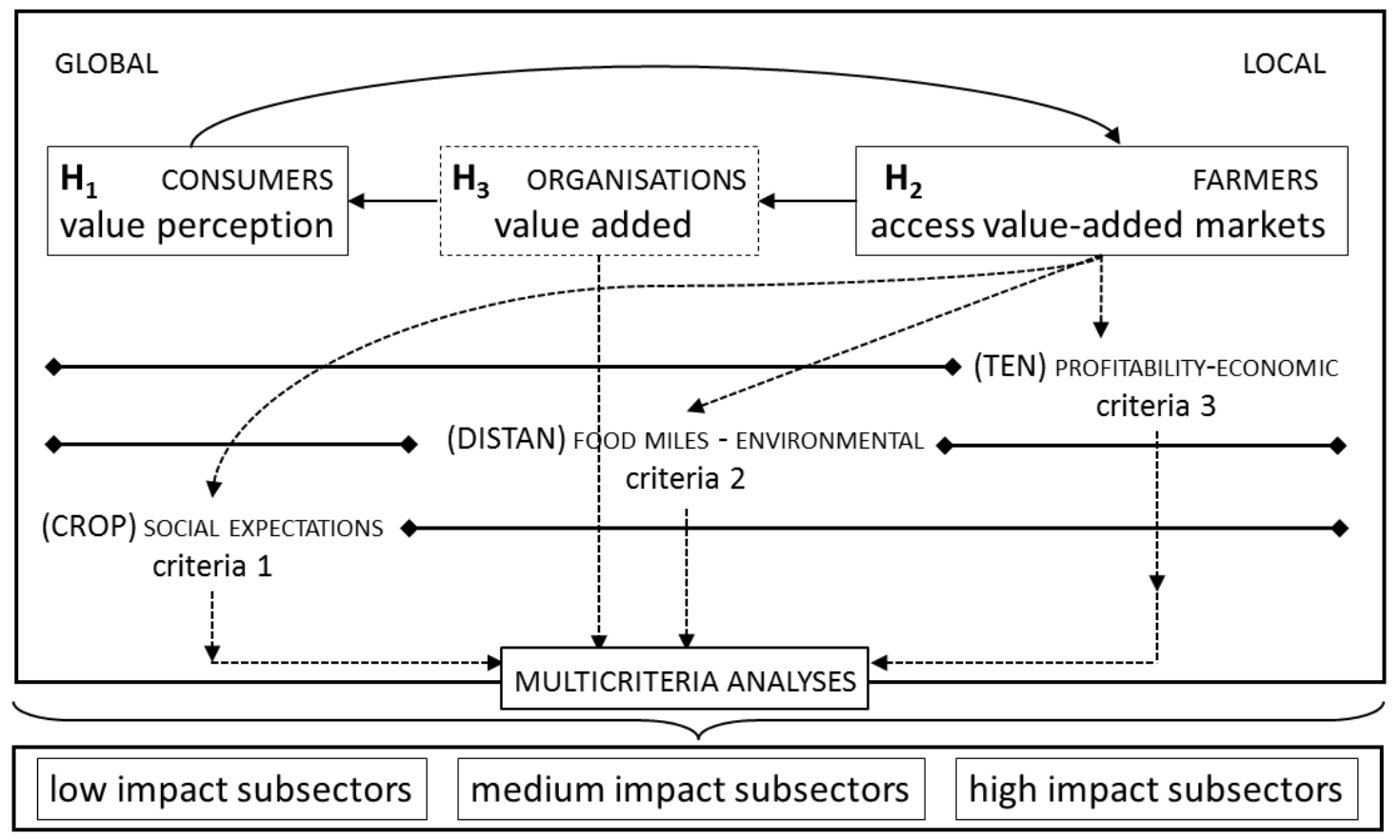




\section{Artículo 3:}

Gómez-Luciano, C.; Vriesekoop, F. and Urbano, B. 2019. Towards Food Security of Alternative Dietary Proteins: a Comparison between Spain and the Dominican Republic. Amfiteatru Economic, 21(51), pp. 393-407. DOI: 10.24818/EA/2019/51/393. Publicado en mayo de 2019.

Base de indexación JCR

Índice de impacto 1,238 (Año 2018) (Q2)

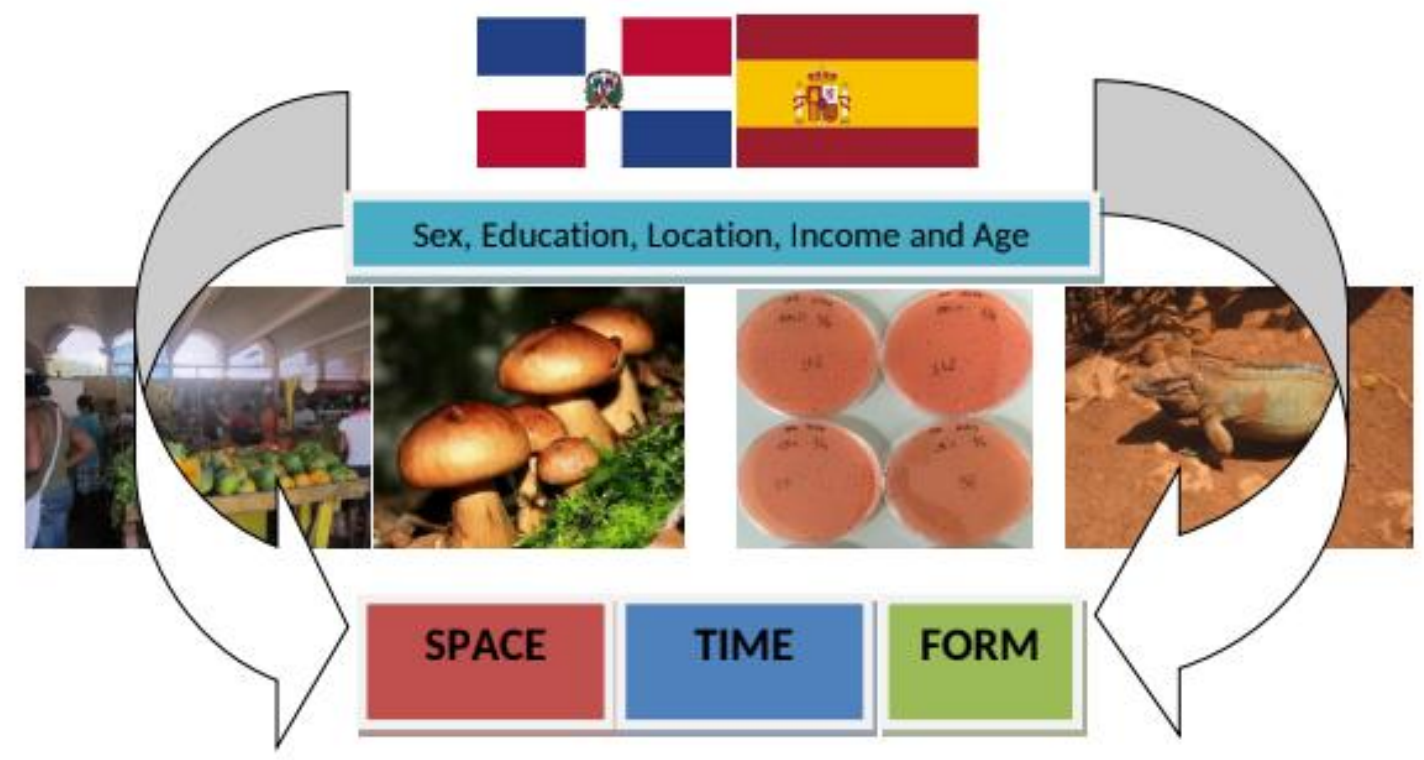




\section{Artículo 4:}

Gómez-Luciano, C.; de Aguiar, L.; Vriesekoop, F. and Urbano, B. 2019. Consumers'willingness to purchase three alternative proteins to meat in United Kingdom, Spain, Brazil and the Dominican Republic. Food Quality and Preference.

Aceptado el 25 de junio de 2019.

DOI: 10.1016/j.foodqual.2019.103732

Base de indexación JCR

Índice de impacto 3,684 (Año 2018) (Q1)

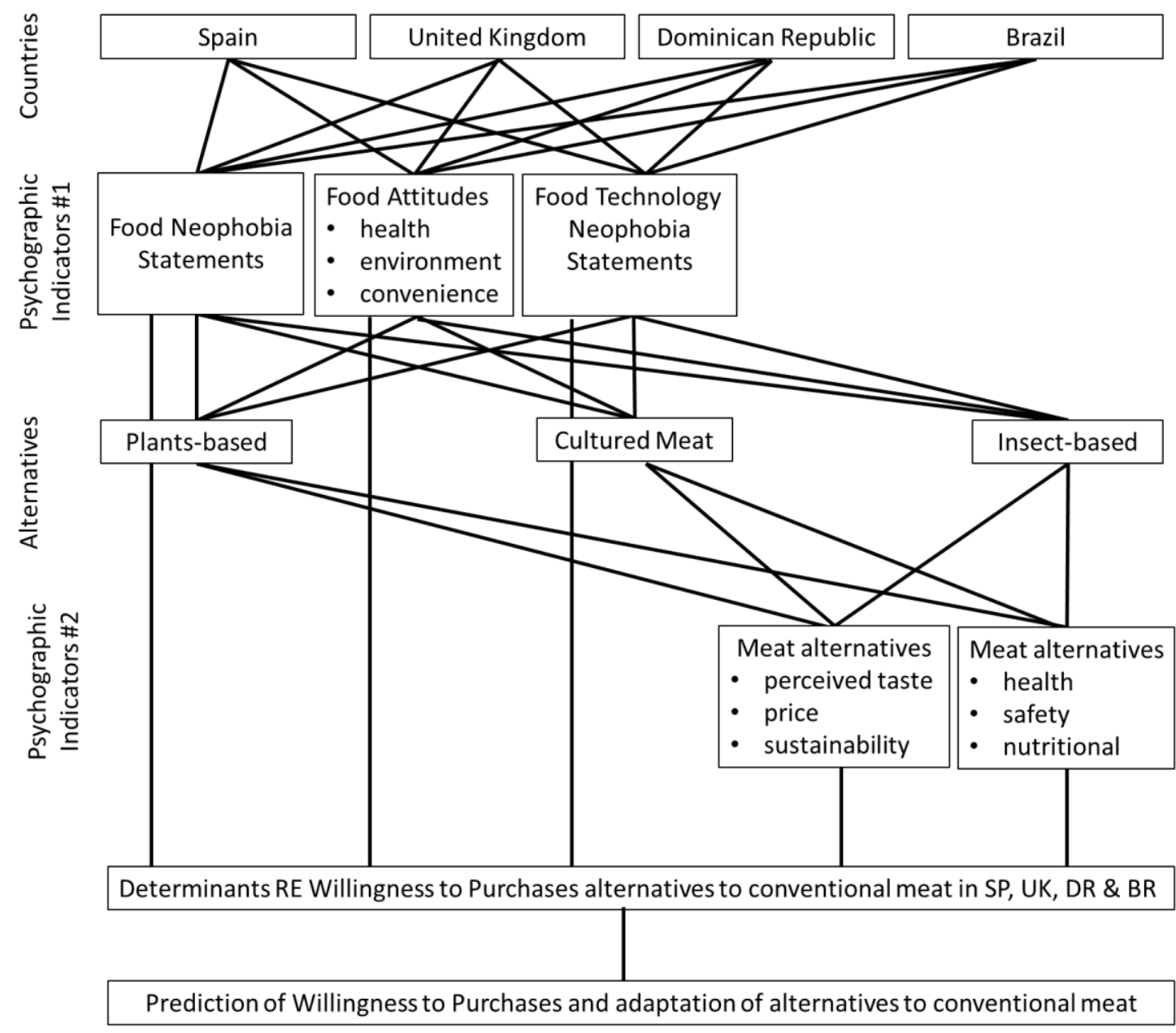




\section{RESULTADOS GENERALES Y DISCUSIÓN}

\section{Eslabón de la distribución}

Los distribuidores creen que los consumidores prefieren el tamaño en los productos mientras que los dominicanos revelaron que prefieren en frutas y hortalizas en primer lugar el sabor, seguido del color y la madurez. Los minoristas consideran que para el consumidor el precio se sitúa en el tercer lugar de preferencia, mientras que el consumidor lo sitúa en cuarto lugar y los mayoristas en sexto lugar. Se confirma una asimetría de información en la cadena de valor agroalimentaria dominicana que conlleva la falta de transparencia, inclusión y de posible respuesta a los cambios del mercado de los grupos implicados de la cadena (Soosay et al., 2012).

Un tercio de los mayoristas reconoció utilizar fuentes de información en su actuación en el mercado, mientras que el $60 \%$ de los minoristas utilizaba a sus proveedores para informarse de la marcha del mercado. El mercado central cuenta con un servicio de información a los operadores que podrían mejorar la comunicación, transacciones y acceso a la innovación y nuevas tecnologías entre los operadores de la cadena de valor agroalimentaria. Este servicio recoge precios, transacciones y es previsor de escasez de producto/s (Erol et al., 2009; Reefke y Sundaram, 2017).

Los consumidores declararon que los productos locales carecen de higiene y seguridad, mientras que las asociaciones de productores indicaron que carecen de medios para limpiar y acondicionar los productos.

El mercado central dispone de un servicio de acondicionamiento a los productores locales para conseguir que los productos lleguen al mercado central en las condiciones exigidas por los consumidores dominicanos y la distribución. Por todo ello, se demuestra que el mercado central podría inducir una distribución sostenible en la República Dominicana y promover la sostenibilidad de la cadena de valor agroalimentaria.

El análisis del flujo de bienes y servicios a través del canal de distribución en la República Dominicana reveló cinco destinos principales para los productos agroalimentarios i) consumidores, ii) hoteles y resorts, iii) exportación, iv) la industria y v) los comercios. Tres de estos destinos, los supermercados, hoteles y los exportadores son aprovisionados por detallistas $(17,6 \%, 14,7 \%, 5,8 \%)$ más que por mayoristas $(5,0 \%$, $7,0 \%, 3,0 \%)$. Además, el 5,8\% de los mayoristas declaró que se abastece de minoristas, lo cual alarga las cadenas de distribución con intermediarios, encarece el producto, aumenta la huella de carbono y dificulta el abastecimiento. Se obtuvo que existe muy poca integración entre los integrantes de la cadena de valor agroalimentaria (Esfahbodi et al., 2016) amenazando la sostenibilidad de la misma. En este sentido, se obtuvo que podrían eliminarse muchos intermediarios orientando la producción agroalimentaria hacia estos cinco destinos (Dubey et al., 2016). 
El mercado central cuenta con un servicio que fomenta la integración de los productores locales para el suministro del mercado y la eliminación de intermediarios. Mantiene un programa de subvenciones a los productores locales (Erol et al., 2009) que cumplan los requisitos de producción para el transporte de productos hasta el mercado central. Con estas medidas, el mercado central sostiene una cuota de productos locales y contribuye a la sostenibilidad de la cadena de valor agroalimentaria.

Los consumidores señalaron una alta preferencia por productos de importación especialmente entre los jóvenes dominicanos, el 31,25\% de los jóvenes de 15 a 24 años, lo cual aumenta las emisiones de gases de efecto invernadero y $\mathrm{CO}_{2}$ por el transporte, aumenta los residuos y compromete la sostenibilidad ambiental de la cadena de valor agroalimentaria dominicana (Hollos et al. 2012).

Se encontraron muy pocos intermediarios que contasen con alguna certificación ambiental o que reciclasen envases, reutilizasen los residuos y pusieran en práctica los principios de logística inversa (Zhu et al., 2008). Los mayoristas y minoristas declararon que contaban con un $15 \%$ de rechazos que generalmente vendían en mercados menores, tiraban o regalaban. Los técnicos revelaron que faltaba tecnología de reciclaje y reutilización, medios y conocimiento, siendo una gran amenaza a la sostenibilidad ambiental de la cadena de valor agroalimentaria.

El mercado central cuenta con una central de manejo de residuos y se abastece de una central eléctrica próxima para almacenar los productos excedentarios. Mantiene además acuerdos con las asociaciones hoteleras, de industrias agroalimentarias y comerciantes del país para reducir el transporte de alimentos y la huella de carbono (Hsu et al., 2013), utilizando canales más directos, acortando los tiempos de aprovisionamiento y expedición y mejorando la logística inversa.

\section{Eslabón de producción}

Los productores deben aumentar la trazabilidad y seguridad de los productos agroalimentarios locales. En algunos casos los productos dominicanos pueden mejorar su calidad y seguridad (Fold, 2008) aunque en otros casos se comprobó que se trata de una cuestión de percepción del consumidor. Se obtuvo una baja percepción de los productos locales entre los consumidores dominicanos y una preferencia por los productos importados poniendo en peligro la sostenibilidad de la cadena de valor agrícola de los productos agroalimentarios dominicanos (Clark e Inwood, 2016).

El modelo de comercialización de los productores reveló que ser productor de café, plátano orgánico o aguacate frente a ser productor de arroz, batata o judías aumentaba la probabilidad de acceso a cadenas de valor potencialmente sostenibles. El tener el terreno de cultivo en propiedad frente a arrendado o cedido y estar situado a menos de cinco kilómetros de un centro de contratación de productos 
agroalimentarios aumenta la probabilidad de participar en cadenas de valor de potencial sostenibilidad. Los resultados coinciden con Fold (2008) que indicó que el acceso a mercados de valor depende del sector y la capacidad de almacenamiento y transporte de los productores. La capacidad de gestión, administración y logística de los productores también condicionará su acceso a los mercados de valor (Caceres, 2015). Fold (2008) mantiene que se necesitan recursos para acceder a mercados de valor, entre ellos la propiedad de la tierra, capacidad de transporte y almacenamiento, o las líneas de financiación necesarias para conseguirlos (Tobin et al., 2016). Los productores dominicanos carecen de medios, capacitación y acceso a la financiación que les permitiría el acceso a cadenas de valor y su sostenibilidad.

La ordenación multicriterio de los sectores agrícolas por vulnerabilidad indica que los sectores más vulnerables en alcanzar cadenas de valor sostenibles son el arroz, la batata y la alubia. Los sectores mejor posicionados son el plátano orgánico, el café y el aguacate. El plátano ecológico de exportación resultó el mejor posicionado para alcanzar una cadena de valor sostenible. El plátano ecológico resultó indiferente al café. El café está mejor posicionado que el arroz y las judías. El guandul está mejor posicionado que el arroz, las batatas y las judías. Las judías resultaron mejor posicionadas que la batata.

Se necesita una reestructuración de los sectores agrícolas más vulnerables hacia la sostenibilidad (Bloom y Hinrichs, 2010). Entre las propuestas se baraja la diversificación de los cultivos, la mejora de los mercados y la percepción de los consumidores locales, la mejora de la logística de la distribución, la aproximación de los terrenos a los centros de contratación (Tolentino-Zondervan et al., 2016).

\section{Eslabón consumidor}

En la República Dominicana se encontró la mayor neofobia alimentaria con respecto a países de mayor desarrollo económico como el Reino Unido, España o Brasil lo que indicaría un posible menor cambio de la demanda alimentaria hacia un consumo sostenible.

Entre las proteínas alternativas a la carne, de origen vegetal, setas, carne cultivada e insectos, la más preferida por los consumidores fueron las proteínas vegetales y puede deberse a que es la alternativa más conocida y disponible para los consumidores con un mercado consolidado frente a los insectos o la carne cultivada que están en desarrollo y poco generalizados. Se obtuvo que el 36,7\% de los dominicanos estarían dispuestos a comprar vegetales como proteínas alternativas a la carne.

La conveniencia y la salud pueden condicionar el cambio alimentario que podría indicar un cambio en toda la cadena de valor agroalimentaria dominicana hacia la sostenibilidad. 
En cuanto a alimentos sostenibles ambientalmente y favorables para la salud como los insectos como sustitutivos a la carne, en la República Dominicana se encontraron los niveles más bajos de aceptación. La alternativa menos preferida fueron los insectos en la República Dominicana. En este sentido, los dominicanos mostraron la menor percepción que las proteínas de insectos sean saludables, sostenibles, seguras o nutritivas. Los dominicanos encuentran este producto repugnante como alimento, para más del $80 \%$ de los consultados. A pesar que diversos autores proponen los insectos como un producto para combatir el hambre en países en desarrollo, de los que se podrían beneficiar 4 mil millones de habitantes con necesidades nutricionales en el mundo, los dominicanos piensan significativamente diferente a los británicos, españoles o brasileños que los insectos no son nutritivos, saludables ni seguros.

En el caso de las decisiones de compra sostenibles para las proteínas alternativas a la carne analizadas, se ha demostrado una menor posible adopción en la República Dominicana con respecto a países de mayor desarrollo económico como Reino Unido o España, que puede incidir en una ralentización de la demanda hacia una cadena de valor sostenible en República Dominicana. En Reino Unido, España y Brasil los consumidores prefirieron como proteínas alternativas a la carne, en primer lugar los productos vegetales, seguidos de la proteína de insectos y finalmente la carne cultivada, mientras que los dominicanos preferían en último lugar la proteína de insectos que les parece menos saludables, seguros, nutritivos, sostenibles y de menor sabor y más caros que la carne tradicional. Las características de los sustitutivos y atributos de sabor, sostenibilidad y precio comparados con la carne tradicional son determinantes y más importantes que la salud, conveniencia y medio ambiente, neofobia alimentaria y tecnología alimentaria neofobia a la hora de comprar sustitutivos sostenibles a la carne tradicional. Se ha demostrado que el aumento en una unidad de la percepción de los dominicanos sobre la salud, seguridad y valor nutricional de las proteínas de insectos conllevaría un incremento del 58,6\% la disposición a comprar esta alternativa a la carne tradicional.

La edad, el sexo y la educación de los dominicanos son factores que pueden determinar un posible cambio alimentario hacia estas proteínas alternativas a la carne. Se obtuvo que los hombres dominicanos de mediana edad y con estudios universitarios podrían ser los posibles primeros adoptadores de estas proteínas alternativas a la carne.

Se encontró que los hombres dominicanos tenían una mayor probabilidad que las mujeres a probar proteínas alternativas como las micoproteínas y la carne cultivada. Los dominicanos con estudios estaban dispuestos a pagar un mayor precio por las micoproteínas y la carne cultivada que por la carne tradicional. Serían los precursores de dietas sostenibles. En cuanto a la preparación, los dominicanos mostraron una gran preferencia por las comidas de preparación y de lento cocinado. 
La reducción de las variables de la neofobia alimentaria reveló que depende del producto sustitutivo y su grado de desarrollo en el mercado. En el caso de los sustitutivos vegetales con amplia implantación en el mercado la neofobia alimentaria se diluye con las decisiones de conveniencia (Tabla 3).

Tabla 3. Vectores propios del análisis de componentes principales de las plantas como proteínas. Componentes rotados utilizando varimax.

\begin{tabular}{|c|c|c|c|c|}
\hline \multirow[b]{2}{*}{ Variables de sustitutivos vegetales } & \multicolumn{4}{|c|}{ Componentes principales } \\
\hline & 1 & 2 & 3 & 4 \\
\hline FNS & & & & 0.589 \\
\hline FTNS & & 0.802 & & \\
\hline Decisiones de salud en alimentación & & & 0.527 & \\
\hline Decisiones de conveniencia & & & & 0.817 \\
\hline Decisiones medioambientales & & & 0.865 & \\
\hline Características del producto & 0.865 & & & \\
\hline Características comparadas a carne & 0.829 & & & \\
\hline
\end{tabular}

En el caso de la carne cultivada y los insectos, sustitutivos con un mercado poco desarrollado, la neofobia tiene se propio componente principal que engloba la neofobia a nuevos alimentos y a la nueva tecnología alimentaria.

Tabla 4. Vectores propios del análisis de componentes principales de las plantas como proteínas. Componentes rotados utilizando varimax.

\begin{tabular}{llll}
\hline & \multicolumn{3}{l}{ Componentes principales } \\
\cline { 2 - 4 } Variables de carne cultivada & 1 & 2 & 3 \\
\hline FNS & & 0.690 \\
FTNS & & 0.616 & \\
Decisiones de salud en alimentación & & 0.673 & \\
Decisiones de conveniencia & 0.875 & 0.662 & \\
Decisiones medioambientales & & \\
Características del producto & 0.883 & & 3 \\
Características comparadas a carne & 1 & 2 & 0.653 \\
Variables de insectos como alimento & & & \\
\hline FNS & & & \\
FTNS & & 0.510 & \\
Decisiones de salud en alimentación & & 0.696 & \\
Decisiones de conveniencia & & & \\
Decisiones medioambientales & & & \\
Características del producto & & & \\
Características comparadas a carne & 0.803 & & \\
\hline
\end{tabular}

FNS= Escala neofobia alimentaria, FTNS=Escala de neofobia tecnología alimentaria

A continuación se presenta un resumen de los principales resultados junto con su aportación práctica y metodológica a la sostenibilidad de la cadena de valor agroalimentaria (Tabla 5). 
Tabla 5. Principales resultados y contribuciones prácticas y metodológicas de la investigación para cada objetivo y materiales empleados.

\begin{tabular}{|c|c|c|c|c|}
\hline OBJETIVO & MATERIAL & RESULTADOS & CONTRIBUCIÓN PRÁCTICA & CONTRIBUCIÓN MÉTODO \\
\hline \multicolumn{5}{|c|}{ Eslabón de la distribución } \\
\hline $\begin{array}{l}\text { Conocer el } \\
\text { funcionamiento del } \\
\text { mercado central }\end{array}$ & $\begin{array}{l}\text { Gerente y director } \\
\text { de Merca Santo } \\
\text { Domingo }\end{array}$ & $\begin{array}{l}\text { Servicio información } \\
\text { Acondicionamiento } \\
\text { Integración } \\
\text { Gestión de residuos }\end{array}$ & \begin{tabular}{|l} 
Mejora flujo información \\
Mejora flujo productos \\
Elimina intermediarios \\
Gestión sostenible
\end{tabular} & $\begin{array}{l}\text { Observación directa } \\
\text { Observación directa } \\
\text { Métodos cualitativos } \\
\text { Observación directa }\end{array}$ \\
\hline $\begin{array}{l}\text { Caracterizar el flujo } \\
\text { de bienes, } \\
\text { información y } \\
\text { servicios en el } \\
\text { eslabón mayorista }\end{array}$ & $\begin{array}{l}24 \text { mayoristas de } \\
\text { Merca Santo } \\
\text { Domingo }\end{array}$ & $\begin{array}{l}\text { Preferencia tamaño } \\
\text { Aumenta transporte } \\
\text { Falta certificación } \\
\text { ambiental }\end{array}$ & $\begin{array}{l}\text { Asimetría de información } \\
\text { Mayor huella de carbono } \\
\text { Reciclar y reutilizar } \\
\text { desechos }\end{array}$ & $\begin{array}{l}\text { Métodos cualitativos } \\
\text { Métodos cuantitativos } \\
\text { Métodos cualitativos }\end{array}$ \\
\hline $\begin{array}{l}\text { Identificar la } \\
\text { actividad de los } \\
\text { minoristas } \\
\end{array}$ & $\begin{array}{l}30 \text { minoristas de } \\
\text { Merca Santo } \\
\text { Domingo }\end{array}$ & $\begin{array}{l}\text { Abastecen mayoristas } \\
\text { Falta certificación } \\
\text { ambiental }\end{array}$ & $\begin{array}{l}\text { Canales comerciales largos } \\
\text { Reciclar y reutilizar } \\
\text { desechos }\end{array}$ & $\begin{array}{l}\text { Paneles de expertos } \\
\text { Métodos cualitativos }\end{array}$ \\
\hline $\begin{array}{l}\text { Evaluar la actuación } \\
\text { de las asociaciones } \\
\text { de productores en la } \\
\text { cadena de valor }\end{array}$ & $\begin{array}{l}18 \text { expertos de } \\
\text { asociaciones de } \\
\text { productores, } \\
\text { técnicos y sociedad } \\
\text { civil }\end{array}$ & $\begin{array}{l}\text { Faltan medios } \\
\text { Ausencia economía } \\
\text { circular }\end{array}$ & $\begin{array}{l}\text { Mejorar } \\
\text { limpieza/acondicionamiento } \\
\text { Certificación ambiental }\end{array}$ & $\begin{array}{l}\text { Métodos cualitativos } \\
\text { Métodos cualitativos }\end{array}$ \\
\hline \multicolumn{5}{|c|}{ Eslabón de la producción } \\
\hline $\begin{array}{l}\text { Conocer los } \\
\text { problemas del } \\
\text { eslabón de la } \\
\text { producción hacia } \\
\text { cadenas de valor } \\
\text { sostenibles }\end{array}$ & $\begin{array}{l}234 \text { productores de } \\
\text { Barahona }\end{array}$ & $\begin{array}{l}\text { Depende de } \\
\text { subsector, } \\
\text { Distancia y } \\
\text { Propiedad }\end{array}$ & $\begin{array}{l}\text { Café, plátano y aguacate } \\
\text { mejor situados }\end{array}$ & $\begin{array}{l}\text { Análisis multicriterio } \\
\text { Modelo de regresión }\end{array}$ \\
\hline $\begin{array}{l}\text { Evaluar el grado de } \\
\text { conexión entre la } \\
\text { demanda delos } \\
\text { consumidores, la } \\
\text { producción y la } \\
\text { distribución }\end{array}$ & $\begin{array}{l}402 \text { consumidores } \\
\text { de Santo Domingo }\end{array}$ & $\begin{array}{l}\text { Falta trazabilidad y } \\
\text { seguridad alimentos }\end{array}$ & $\begin{array}{l}\text { Preferencia productos } \\
\text { importados }\end{array}$ & $\begin{array}{l}\text { Entrevistas con análisis } \\
\text { cualitativo y cuantitativo }\end{array}$ \\
\hline \multicolumn{5}{|l|}{ Eslabón consumidor } \\
\hline $\begin{array}{l}\text { Conocer el grado de } \\
\text { sustitución hacia un } \\
\text { consumo sostenible }\end{array}$ & $\begin{array}{l}983 \text { consumidores } \\
\text { de } 4 \text { países }\end{array}$ & $\begin{array}{l}\text { Depende desarrollo } \\
\text { económico, } \\
\text { Producto, } \\
\text { Percepción }\end{array}$ & $\begin{array}{l}\text { Menor disposición comprar } \\
\text { Más vegetal, menos insecto } \\
\text { Conveniencia y salud }\end{array}$ & Modelos de predicción \\
\hline $\begin{array}{l}\text { Analizar el perfil de } \\
\text { los consumidores } \\
\text { sostenibles }\end{array}$ & $\begin{array}{l}401 \text { consumidores } \\
\text { de España y } \\
\text { República } \\
\text { Dominicana }\end{array}$ & $\begin{array}{l}\text { Edad } \\
\text { Sexo } \\
\text { Educación }\end{array}$ & $\begin{array}{l}\text { Hombres } \\
\text { Mediana edad } \\
\text { Con estudios }\end{array}$ & Análisis cuantitativo \\
\hline \multicolumn{5}{|c|}{ Visión holística de la cadena de valor agroalimentaria } \\
\hline $\begin{array}{l}\text { Evaluar } \\
\text { sostenibilidad de la } \\
\text { cadena de valor } \\
\text { agroalimentaria }\end{array}$ & $\begin{array}{l}11 \text { técnicos, } \\
\text { investigadores, } \\
\text { ciudadanos y } \\
\text { agentes de la } \\
\text { cadena }\end{array}$ & $\begin{array}{l}\text { Faltan medios } \\
\text { respetuosos MA } \\
\text { Necesidad de } \\
\text { reestructurar sector }\end{array}$ & \begin{tabular}{|l|} 
Desarrollo de productos \\
sustitutivos, adaptados al \\
mercado, respetuosos y \\
sostenibles
\end{tabular} & $\begin{array}{l}\text { Análisis descriptivo } \\
\text { cualitativo }\end{array}$ \\
\hline
\end{tabular}




\section{CONCLUSIONES GENERALES}

\section{Eslabón distribuidor}

En el eslabón de los distribuidores se concluye una baja integración entre los agentes de la cadena de valor y bajo flujo de información entre los consumidores, productores y distribuidores que pueden comprometer la sostenibilidad social de la cadena de valor agroalimentaria. Por su parte, el servicio de información del mercado central puede mejorar el flujo de información entre los eslabones favoreciendo el acceso a la tecnología y la innovación a todos los agentes de la cadena y mejorando las transacciones.

La logística de la distribución se debería centrar en el flujo de bienes y servicios a cinco destinos principales para los productos agroalimentarios i) consumidores, ii) hoteles y resorts, iii) exportación, iv) la industria y v) los comercios. Ello permitiría la eliminación de intermediarios y acortar los canales de distribución mejorando la sostenibilidad económica de la cadena de valor agroalimentaria.

Se concluye una baja certificación ambiental y la falta de medios, tecnología y capacitación para llevar a cabo una logística inversa con aprovechamiento de residuos, reutilización excedentes y una logística de transporte eficiente que permita reducir los gases de efecto invernaderos y emisiones de $\mathrm{CO}_{2}$. Esta circunstancia puede comprometer la sostenibilidad ambiental de la cadena de distribución agroalimentaria. En este sentido, el mercado central cuenta con un sistema de gestión de residuos y con frigoríficos para el almacenamiento de excedentes así como subvenciones para facilitar el transporte y la logística ambientalmente eficiente en el país contribuyendo a la sostenibilidad de la cadena de valor agroalimentaria en la República Dominicana.

\section{Eslabón productor}

Los productores raramente tienen en cuenta los gustos y preferencias de los consumidores finales lo cual hace que no lo consideren en sus decisiones de producción y comprometan la sostenibilidad de toda la cadena de valor agroalimentaria.

El acceso de los productores a la cadena de valor sostenible depende del sector al que pertenecen, de los medios que disponen y la distancia a la que se encuentren de los centros de contratación. Se requiere de recursos para acceder a la cadena de valor sostenible y los productores dominicanos carecen de medios, capacitación y tecnologías necesarias para inducir una cadena de valor sostenible. Se necesitan medidas de acompañamiento, formación y medios que aseguren la transición a cadenas de valor sostenibles. 
No todos los sectores agrícolas de la República Dominicana se encuentran igual situados en el camino hacia la sostenibilidad de la cadena de valor. Los sectores mejor posicionados son el plátano orgánico, el café y el aguacate con un mayor potencial de sostenibilidad de la cadena de valor, mientras que los sectores del arroz, la judía y la batata tienen menos potencial de sostenibilidad de la cadena de valor.

En base al posicionamiento que tienen los sectores agrícolas en sostenibilidad se recomienda la reestructuración de los sectores menos sostenibles que permitan a los productores garantizar la rentabilidad.

\section{Eslabón consumidor}

El eslabón consumidor dominicano mostró una baja sensibilidad a dietas sostenibles y su aplicación al caso de los sustitutivos a la carne, con respecto a los países de mayor desarrollo económico analizados. Se puede concluir una lenta transición del eslabón consumidor dominicano hacia dietas sostenibles y por lo tanto una lenta incidencia en los eslabones de la distribución y la producción y la sostenibilidad de la cadena de valor agroalimentaria dominicana.

La demanda influirá lentamente en conseguir una cadena de valor agroalimentaria sostenible en la República Dominicana con respecto a los cambios que se están produciendo para este indicador en países con mayor desarrollo económico.

El perfil de dominicanos que podría inducir el cambio hacia la dieta y la cadena de valor agroalimentaria sostenible serían hombres, de mediana edad y con estudios.

La mayor neofobia y reticencia a los productos de innovación tecnológica alimentaria indica que la transición en la República Dominicana a dietas sostenibles deberá producirse con alimentos bien conocidos y disponibles por los dominicanos y mediante adaptaciones de productos tradicionales bien valorados de la cocina criolla.

Las características de sabor, sostenibilidad y precio comparados con otros alimentos menos sostenibles son determinantes y más importantes para los dominicanos que la salud, la conveniencia y medio ambiente, la neofobia alimentaria y a la tecnología a la hora de comprar sustitutivos sostenibles.

\section{Implicaciones prácticas}

Esta investigación contribuye a un mejor conocimiento de la complejidad y entramado de relaciones que se dan en la cadena de valor agroalimentaria y que hacen necesario su análisis desde un punto de vista holístico.

La presente investigación permitirá a los decisores, gestores, distribuidores y productores tomar decisiones hacia la cadena de valor agroalimentaria sostenible. La 
visión holística del trabajo considerando los eslabones de la cadena más importante permitirá considerar las relaciones entre los eslabones y los agentes implicados.

Esta investigación, revela la necesidad de una mayor implicación de las políticas del país para una gestión ambientalmente sostenible de la cadena de valor mediante el desarrollo de medidas ambientales, tecnología y formación adecuadas. Un cambio de paradigma en el consumo alimentario y una revalorización de los productos respetuosos con el medio ambiente locales.

Esta investigación permitirá acompañar a los productores vulnerables para acceder a cadenas de valor sostenibles. El conocimiento de los factores determinantes como la necesidad de medios, capacitación y recursos para llevar una comercialización sostenible agroalimentaria ayudará a los gestores en implantar políticas de acompañamiento a los sectores más vulnerables en su acceso a cadenas de valor sostenibles.

\section{Futuras líneas de investigación}

El presente trabajo de investigación ha dado lugar a diferentes líneas de trabajo futuras. La investigación futura requeriría considerar y ampliar el número de eslabones considerados. Cuanto mayor fuese el número de agentes, grupos de interés, distribuidores y eslabones de la cadena de valor considerado, mayor sería la precisión del análisis. Las interrelaciones entre la industria relacionada, el sector del transporte, almacenamiento y otros agentes vinculados a la cadena de valor podría dar una imagen más precisa de la sostenibilidad de la cadena de valor agroalimentaria.

Sería de interés comparar la huella de carbono de los productos agroalimentarios dominicanos y las importaciones, pudiendo establecer el consumo más respetuoso con el medio ambiente y con menores emisiones en el país. También sería de interés desarrollar medidas específicas en la República Dominicana de logística inversa y técnicas de distribución ambientalmente sostenible que cuente con reciclado de residuos, reutilización de excedentes y una optimización del canal de distribución agroalimentario.

Sería de interés analizar cómo la falta de sostenibilidad de la cadena de valor afecta a la malnutrición y al hambre de la población. Para ello, sería interesante utilizar los indicadores de inseguridad alimentaria de los trabajos previos como FANTA.

Sería de interés analizar cómo varían las variables psicográficas así como los criterios medioambientales, de salud y sostenibilidad, y las decisiones de compra con respecto a la información que se difunde en los medios de comunicación, propaganda positiva y negativa que se hace de los medios de comunicación de los diferentes sustitutivos sostenibles alimentarios. Resultaría interesante evaluar la evolución del marketing agroindustrial y los mensajes enviados a los consumidores. 
Sería de interés profundizar en las medidas de acompañamiento para la adaptación de los grupos más vulnerables a cadenas de valor sostenibles por parte de las administraciones, los gestores, los grupos de interés y la sociedad civil. Se trata de medidas que cuenten con recursos, tecnología, capacitación y los medios necesarios. 


\section{BIBLIOGRAFÍA}

- Ashby, A., Leat, M., Hudson-Smith, M. 2012. Making connections: a review of supply chain management and sustainability literature. Supply Chain Management: International Journal, 17 (5), 497-516. DOI 10.1108/13598541211258573

- Austin, K. 2010. The "Hamburger Connection" as ecologically unequal exchange: A cross-national investigation of beef exports and deforestation in less-developed countries. Rural Sociology, 75(2), 270-299. DOI 10.1111/j.15490831.2010.00017.x

- Ballard, T., Coates, J., Swindale, A., Deitchler, M. 2011. Household Hunger Scale: Indicator Definition and Measurement Guide. FANTA-2 Bridge, FHI 360. Washington, DC.

- Balbi, L., Darboe, M. 2010. Crop and Food Security assessment Mission to Mozambique. World Food Programme. Food and Agriculture Organization of the United Nations. Rome.

- Bryant, C., Barnett, J. 2018. Consumer acceptance of cultured meat: A systematic review. Meat Science, 143, 8-17. DOI 10.1016/j.meatsci.2018.04.008

- Borras, S.M., Franco, J.C., Isakson, S.R., Levidow, L., Vervest, P. 2016. The rise of flex crops and commodities: Implications for research. Journal of Peasant Studies, 43, 93-115. DOI 10.1080/03066150.2015.1036417

- Bloom, D., Hinrichs, C.C. 2010. Moving local food through conventional food system infrastructure: Value chain framework comparisons and insights. Renewable Agriculture and Food Systems, 26, 13-23.

- Caceres, D.M. 2015. Accumulation by dispossession and socio-environmental conflicts caused by the expansion of agribusiness in Argentina. Journal of Agrarian Change, 15, 116-147. DOI 10.1111/joac.12057

- Candel, M.J.J.M. 2001. Consumers' convenience orientation towards meal preparation: Conceptualization and measurement. Appetite, 36, 15-28. DOI 10.1006/appe.2000.0364

- Caparros Megido, R., Sablon, M.L., Geuens, M., Brostaux, Y., Alabi, T., Blecker, C., Drugmand, D., Haubruge, E., Francis, F. 2014. Edible insects' acceptance by Belgian consumers: promising attitude for Entomophagy development. Journal of Sensory Studies, 29, 14-20. DOI 101111/joss12077

- Challies, E.R.T., Murray, W.E. 2011. The interaction of Global Value Chains and Rural Livelihoods: The case of Smallholder Raspberry Grower in Chile. Journal of Agrarian Change, 11, 29-59. DOI 10.1111/j.1471-0366.2010.00282.x

- Chin, T.A., Tat, H.H. 2015. Does gender diversity moderate the relationship between supply chain management practice and performance in the electronic manufacturing services industry? International Journal of Logistic Research Applied, 18(1), 35-45. DOI 10.1080/13675567.2014.945399 
- Clark, J.K., Inwood, S.M. 2016. Scaling-up regional fruit and vegetable distribution: potential for adaptive change in the food system. Agriculture and Human Value, 33, 503-519. DOI 10.1007/s10460-015-9618-7

- Clarys, P., Deliens, T., Huybrechts, I., Deriemaeker, P., Vanaelst, B., De Keyzer, W., Hebbelinck, M., Mullie, P. 2014. Comparison of nutritional quality of the vegan, vegetarian, semi-vegetarian, pesco-vegetarian and omnivorous diet. Nutrients, 6(3), 1318-1332. DOI 10.3390/nu6031318

- Cox, D.N., Evans, G. 2008. Construction and validation of a psychometric scale to measure consumers' fears of novel food technologies: the Food Technology Neophobia Scale. Food Quality and Preference, 1, 704-710. DOI 10.1016/j.foodqual.2008.04.005

- Damsbo-Svendsen, M., Frøst, M.B., Olsen, A. 2017. A review of instruments developed to measure food neophobia. Appetite, 1, 358-367. DOI 10.1016/j.appet.2017.02.032

- Dam, L., Petkova, B.N., 2014. The impact of environmental supply chain sustainability programs on shareholder wealth. Int. J. Oper. Prod. Manag. 34 (5), 586e609. DOI 10.1108/IJOPM-10-2012-0482

- De Boer, J., Hoogland, C.T. Boersema, J.J. 2007. Towards more sustainable food choices. Value priorities and motivational orientations. Food Quality and Preference, 18, 985-996. DOI 10.1016/j.foodqual.2007.04.002

- De Boer, J., Aiking, H. 2011. On the merits of plant-based proteins for global food security. Marrying macro and micro perspectives. Ecological Economics, 70(7), 1259-1265. DOI 10.1016/j.ecolecon.2011.03.001

- De Boer, J., Schösler, H., Aiking, H. 2014. "Meatless days" or "less but better"? Exploring strategies to adapt Western meat consumption to health and sustainability challenges. Appetite, 76, 120-128. DOI 10.1016/j.appet.2014.02.002

- DeFoliart, G. 2010. An overview of the role of edible insects in preserving biodiversity. Ecology of Food and Nutrition, 36, 109-132. DOI 10.1080/03670244.1997.9991510

- Deitchler, M., Ballard, T., Swindale, A., Coates, J. 2011. Introducing a Simple. Measure of Household Hunger for Cross-Cultural Use. Security. FANTA-2 Bridge, FHI 360. Washington, DC.

- Ding, H., Liua, Q., Zheng, L. 2016. Assessing the economic performance of an environmental sustainable supply chain in reducing environmental externalities. European Journal Operational Research, 255, 463-480. DOI 10.1016/j.ejor.2016.05.003

- Dovey, T.M., Staples, P.A., Gibson, E.L., Halford, J.C. 2008. Food neophobia and "picky/fussy" eating in children: A review. Appetite, 50, 181-193. DOI 10.1016/j.appet.2007.09.009 
- Dubey, R., Gunasekaran, A., Papadopoulos, T., Childe, S.J., Shibin, K.T., Wamba, F. 2016. Sustainable supply chain management: framework and further research directions. Journal of Cleaner Production, 142(2), 1119-1130. DOI 10.1016/j.jclepro.2016.03.117

- Erol, I., Cakar, N., Erel, D., Sari, R. 2009. Sustainability in the Turkish retailing industry. Sustainable Development, 17, 49-67. DOI 10.1002/sd.369

- Esfahbodi, A., Zhang, Y., Watson, G. 2016. Sustainable supply chain management in emerging economies: trade-offs between environmental and cost performance. International Journal of Production Economics. DOI 10.1016/j.ijpe.2016.02.013i

- FANTA. 2005. Measuring Household Food Insecurity Workshop II Report: October 19, 2005. Washington, DC: FANTA, AED.

- FAO. 2019. Estadísticas sobre seguridad alimentaria. Organización de las Naciones Unidas para la Agricultura y la Alimentación. http://www.fao.org/economic/ess/ess-fs/es/

- Foer, J.S. 2010. Eating animals. Penguin Books. London.

- Frohmann, A., Herreros, S., Mulder, N., Olmos, X., 2012. Carbon Footprint and Food exports: Guidelines. Latam Economic Comission of the United Nations. New York.

- Fold, N. 2008. Transnational Sourcing Practices in Ghana's Perennial Crop Sectors. Journal of Agrarian Change, 8, 94-122. DOI 10.1111/j.14710366.2007.00164.x

- Gerber, P.J., Steinfeld, H., Henderson, B., Mottet, A., Opio, C. Dijkman, J. 2013. Tackling climate change through livestock. A global assessment of emissions and mitigation opportunities. Food and Agriculture Organization of the United Nations (FAO). Roma.

- Gmuer, A., Nuessli Guth, J., Hartmann, C., Siegrist, M. 2016. Effects of the degree of processing of insect ingredients in snacks on expected emotional experiences and willingness to eat. Food Quality and Preference, 54, 117-127. DOI 10.1016/j.foodqual.2016.07.003

- Gómez-Luciano, C.A., Vriesekoop, F., Urbano, B. 2019. Towards Food Security of Alternative Dietary Proteins: a Comparison between Spain and the Dominican Republic. Amfiteatru Economic, 21(51), 393-407. 10.24818/EA/2019/51/393

- Goodwin, J.N., Shoulders, C.W. 2013. The future of meat: A qualitative analysis of cultured meat media coverage. Meat Science, 95, 445-450. DOI 10.1016/j.meatsci.2013.05.027

- Graça, J., Oliveira, A. Cardoso, M.M. 2015. Meat, beyond the plate. Data-driven hypotheses for understanding participant willingness to adopt a more plantbased diet. Appetite, 90(1), 80-90. 10.1016/j.appet.2015.02.037 
- Hartmann, C., Shi, J., Giusto, A., Siegrist, M. 2015. The psychology of eating insects: a cross-cultural comparison between Germany and China. Food Quality and Preference, 44, 148-156. DOI 10.1016/j.foodqual.2015.04.013

- Hayley, A., Zinkiewicz, L., Hardiman, K. 2015. Values, attitudes, and frequency of meat consumption. Predicting meat-reduced diet in Australians. Appetite, 84, 98-106. DOI 10.1016/j.appet.2014.10.002

- Herman, C.P., Polivy, J. 2008. External cues in the control of food intake in humans. The sensory-normative distinction. Physiology \& Behavior, 94, 722-728. DOI 10.1016/j.physbeh.2008.04.014

- Hollos, D., Blome, C., Foerstl, K. 2012. Does sustainable supplier cooperation affect performance? Examining implications for the triple bottom line. International Journal of Production Research. 50(11), 2968-2986. DOI 10.1080/00207543.2011.582184

- Hopwood, B., Mellor, M., OBrien, G. 2005. Sustainable development: mapping different approaches. Sustainable Development, 13, 38-52. DOI 10.1002/sd.244

- House, J. 2016. Consumer acceptance of insect-based foods in the Netherlands: Academic and commercial implications. Appetite, 107, 47-58. DOI 10.1016/j.appet.2016.07.023

- Hsu, C.C., Tan, K.C., Zailani, S.H.M., Jayaraman, V. 2013. Supply chain drivers that foster the development of green initiatives in an emerging economy. International Journal of Operations \& Production Management, 33(6), 656-688. DOI 10.1108/IJOPM-10-2011-0401

- IICA. 2009. Strategic Plan for the Agrarian Sector in Dominican Republic, ed. Dominican Republic Agriculture Ministry. Santo Domingo. Dominican Republic.

- Kearny, J. 2010. Food consumption trends and drivers. Philosophical Transactions of the Royal Society, 365, 2793-2807. DOI 10.1098/rstb.2010.0149

- Keefe, L.M. 2018. \# FakeMeat: How big a deal will animal meat analogs ultimately be? Animal Frontiers, 8(3), 30-37. DOI 10.1093/af/vfy011

- Leguizamon, A. 2016, Disappearing nature? Agribusiness, biotechnology and distance in Argentine soybean production. The Journal of Peasant Studies, 43, 313-330. DOI 10.1080/03066150.2016.1140647

- Loaharanu, P. 2001. Creciente demanda de alimentos inocuos la tecnología de las radiaciones constituye una respuesta oportuna. Boletín del OIEA, 42(2), 3742.

- Lombardi, A., Vecchio, R., Borrello, M., Caracciolo, F., Cembalo, L. 2018. Willingness to pay for insect-based food: the role of information and carrier. Food Quality and Preference, 72, 177-187. DOI 10.1016/j.foodqual.2018.10.001

- Looy, H., Wood J.R. 2006. Attitudes toward invertebrates: are educational "bug banquets" effective? Journal of Environmental Education, 37, 37-48. DOI 10.3200/JOEE.37.2 
- Los, B., Timmer, M.P., Vries, G.J. 2015, How global are global value chains? A new approach to measure international fragmentation, Journal of Regional Science, 55, 66-92. DOI 10.1111/jors.12121

- Murmis, M., Murmis, M.R. 2012, Land concentration and foreign land ownership in Argentina in the context of global land grabbing. Canadian Journal of Development Studies, 33, 490-508.

- Ortiz-Miranda, D., Moragues-Faus, A.M. 2015. Governing fair trade coffee supply: dynamics and challenges in small farmers' organizations. Sustainable Development, 23, 41-54. DOI 10.1002/sd.1570

- Passel, S. 2013. Food miles to assess sustainability: a revision. Sustainable Development, 21, 1-17. DOI 10.1002/sd485

- Pegler, L. 2015. Peasant inclusion in global value chains: economic upgrading but social downgrading in labour processes? The Journal of Peasant Studies, 42, 929-956.

- Pliner, P., Hobden, K. 1992. Development of a scale to measure the trait of food neophobia in humans. Appetite, 19, 105-120. DOI 10.1016/01956663(92)90014-w

- Preston, C.C., Colman, A.M. 2000. Optimal number of response categories in rating scales: reliability validity discriminating power and respondent preferences. Acta Psychologica, 104, 1-15. DOI 10.1016/S0001-6918(99)00050-5

- Post, M.J. 2014. An alternative animal protein source: cultured beef. Annals of the New York Academy of Sciences, 1328, 29-33. DOI 10.1111/nyas.12569

- Prowse, M., Moyer-Lee, J. 2014. A comparative Value Chain Analysis of Smallholder Burley Tobacco Production in Malawi - 2003/4 and 2009/10. Journal of Agrarian Change, 14, 323-346. DOI 10.1111/joac.12022

- Raphaely, T., Marinova, D. 2014. Flexitarianism. Decarbonising through flexible vegetarianism. Renewable Energy, 67, 90-96. DOI 10.1016/j.renene.2013.11.030

- Ras, P.J., Vermeulen, J.V. 2009. Sustainable production and the performance of South african entrepreneurs in a global supply chain. The case of South African table grape producers. Sustainable Development, 17, 325-340. DOI $10.1002 / \mathrm{sd} .427$

- Reefke, H., Sundaram, D. 2017. Key themes and research opportunities in sustainable supply chain management e identification and evaluation. Omega, 66, 195-211. DOI 10.1016/j.omega.2016.02.003

- Reuter, C., Foerstl, K., Hartmann, E., Blome, C. 2010. Sustainable global supplier management: the role of dynamic capabilities in achieving competitive advantage. Journal of Supply Chain Management, 46(2-3), 45-63. DOI 10.1111/j.1745-493X.2010.03189.x

- Rimmington, M., Smith, J.C., Hawkins, R. 2006. Corporate social responsibility and sustainable food procurement. British Food Journal, 108, 824-837. DOI 10.1108/00070700610702082 
- Ritchey, P.N., Frank, R.A., Hursti, U.K., Tuorila, H. 2003. Validation and crossnational comparison of the food neophobia scale (FNS) using confirmatory factor analysis. Appetite, 40, 163-173. DOI 10.1016/S0195-6663(02)00134-4

- Ritzer, G. 2002. Explorations in the sociology of consumption. Journal of Consumer Policy, 25, 460-462. DOI 10.1023/A:1020316218416

- Roberts, J.A. 1996. Green consumers in the 1990s: Profile and implications for advertising. Journal of Business Research, 36, 217-231. DOI 10.1016/01482963(95)00150-6

- Roininen, K., Lähteenmäki, L., Tuorila, H. 1999. Quantification of consumer attitudes to health and hedonic characteristics of foods. Appetite, 33(1), 71-88. DOI 10.1006/appe.1999.0232

- Rothgerber, H. 2015. Can you have your meat and eat it too? Conscientious omnivores, vegetarians, and adherence to diet. Appetite, 84, 196-203. DOI 10.1016/j.appet.2014.10.012

- Ruby, M.B., Rozin, P., Chan, C. 2015. Determinants of willingness to eat insects in the USA and India. Journal of Insects as Food and Feed, 1, 215-225. DOI 10.3920/JIFF2015.0029

- Rutherford, D.D., Burke, H.M., Cheung, K.K., Field, S.H. 2016, Impact of an Agricultural Value Chain Project on Smallholder Farmers, Households, and Children in Liberia. World Development, 83, 70-83.

- Sabaté, J., Soret, S. 2014. Sustainability of plant-based diets: back to the future. The American Journal of Clinical Nutrition, 100, 476S-482S. DOI 10.3945/ajcn.113.071522

- Sadler, M.J. 2004. Meat alternatives - market developments and health benefits. Trends in Food Science \& Technology, 15, 250-260. DOi 10.1016/j.tifs.2003.09.003

- Schosler, H., de Boer, J., Boersema, J.J. 2012. Can we cut out the meat of the dish? Constructing consumer-oriented pathways towards meat substitution. Appetite, 58, 39-47. DOI 10.1016/j.appet.2011.09.009

- Schnettler, B., Crisóstomo, G., Sepúlveda, J., Mora, M., Lobos, G., Miranda, H. 2013. Food neophobia, nanotechnology and satisfaction with life. Appetite, 69, 71-79. DOI 10.1016/j.appet.2013.05.014

- Schouteten, J.J., De Steur, H., De Pelsmaeker, S., Lagast, S., Juvinal, J., De Bourdeaudhuij, I., Verbeke, W., Gellynck, X. 2016. Emotional and sensory profiling of insect- plant- and meat-based burgers under blind expected and informed conditions. Food Quality and Preference, 52, 27-31. DOI 10.1016/j.foodqual.2016.03.011

- Scoones, I. 2009. Livelihoods Perspectives and Rural Development. The Journal of Peasant Studies, 36, 171-196. DOI 10.12691/ajrd-5-4-2

- SESPAS. 2009. Food guides based on Dominican Republic foodstuffs. First Lady's Office and SESPAS. Santo Domingo. Dominican Republic. 
- Sidali, K.L., Pizzo, S., Garrido-Pérez, E.I., Schamel, G. 2019. Between food delicacies and food taboos: A structural equation model to assess Western students' acceptance of Amazonian insect food. Food Research International, 115, 83-89. DOI 10.1016/j.foodres.2018.07.027

- Soper, R. 2016. Local is not fair: indigenous peasant farmer preference for export markets. Agriculture and Human Value, 33, 537-548.

- Soosay, C., Fearne, A., Dent, B. 2012. Sustainable value chain analysis - a case study of Oxford Landing from "vine to dine". Supply Chain Management International Journal, 17(1), 68-77. DOI 10.1108/13598541211212212

- Tan, H.S.G., van den Berg, E., Steger, M. 2016. The influence of product preparation familiarity and individual traits on the consumer acceptance of insects as food. Food Quality and Preference, 52, 222-231. DOI 10.1016/j.foodqual.2016.05.003

- Taylor, D.H., 2005. Supply Chain Analysis: an approach to value chain improvement in agri-food chains. The International Journal of Physical Distribution and Logistics Management, 35(10), 744-761. DOI 10.1108/09600030510634599

- Testa, M., Stillo, M., Maffei, G., Andriolo, V., Gardois, P., Zotti C.M. 2017. Ugly but tasty: A systematic review of possible human and animal health risks related to Entomophagy. Critical Reviews in Food Science and Nutrition, 57, 3747-3759. DOI 10.1080/10408398.2016.1162766

- Tilman, D., Clark, M. 2014. Global diets link environmental sustainability and human health. Nature, 515, 518-522. DOI 10.1038/nature13959

- Trauger, A. 2014. Is bigger better? The small farm imaginary and fair trade banana production in the Dominican Republic. Annals of the Association of the American Geographers, 104, 1082-1100. DOI 10.1080/00045608.2014.923720

- Tobin, D., Brennan, M., Radhakrishna, R. 2016. Food access and pro-poor value chains: a community case study in the central highlands of Peru. Agriculture and Human Value, 33, 895-909. DOI 10.1007/s10460-015-9676-x

- Tolentino-Zondervan, F., Berentsen, P., Bush, S., Idemne, J., Babaran, R., Lansink, A.O. 2016. Comparison of Private Incentive Mechanisms for Improving sustainability of Filipo Tuna Fisheries. World Development, 83, 264-279. DOI 10.1080/1523908X.2018.1461084

- Vanhonacker, F., Van Loo, E.J., Gellynck, X., Verbeke, W. 2012. Flemish consumer attitudes towards more sustainable food choices. Appetite, 62, 7-16. DOI 10.1016/j.appet.2012.11.003

- Van Huis, A. 2013. Potential of insects as food and feeding. Assuring Food Security. Annual review of Entomology, 58, 563-583. DOI 10.1146/annurevento-120811-153704 
- Van Trijp, H.C.M., Steenkamp, J.B.E.M. 1992. Consumers' variety seeking tendency with respect to foods: Measurement and managerial implications. European Review of Agricultural Economics, 19, 181-195.

- Verbeke, W. 2015. Profiling consumers who are ready to adopt insects as a meat substitute in a Western Society. Food Quality and Preference, 39, 147-155. DOI 10.1016/j.foodqual.2014.07.008 0950-3293

- Verbeke, W., Sans, P. Van Loo, E.J. 2015. Challenges and prospects for consumer acceptance of cultured meat. Journal of Integrative Agriculture, 14(2), 285-294. DOI 10.1016/S2095-3119(14)60884-4

- Verkerk, M.C., Tramper, J., van Trijp, J.C.M., Martens, D.E. 2007. Insect cells for human food. Biotechnology Advances, 25, 198-202. DOI 10.1016/j.biotechadv.2006.11.004

- Verneau, F., La Barbera, F., Kolle, S., Amato, M., Del Giudice, T., Grunert, K. 2016. The effect of communication and implicit associations on consuming insects: an experiment in Denmark and Italy. Appetite, 106, 30-36. DOI 10.1016/j.appet.2016.02.006

- Vriesekoop, F., Shaw, R. 2010. The Australian bush fly (Musca vetustissima) as a potential vector in the transmission of foodborne pathogens at outdoor eateries. Foodborne Pathogens and Disease, 7, 275-279. DOI 10.1089/fpd.2009.0366

- Walsh-Dilley, M. 2013. Negotiating hybridity in highland Bolivia: Indigenous moral economy and the expanding market for quinoa. Journal of Peasant Studies, 40, 659-682. DOI 10.1080/03066150.2013.825770

- Wansink, B. 2002. Changing eating habits on the home front. Lost lessons from World War II research. Journal of Public Policy Marketing, 21(1), 90-99. DOI 10.1509/jppm.21.1.90.17614

- Warner, B.P. 2016. Understanding actor-centered adaptation limits in smallholder agriculture in the Central American dry tropics. Agriculture and Human Value, 33, 785-797. DOI 10.1007/s10460-015-9661-4

- Webb, P., Coates, J., Frongillo, E.A., Rogers, B.L., Swindale, A., Bilinsky, P. 2006. Measuring Household Food Insecurity: Why It's So Important and Yet So Difficult to Do. Journal of Nutrition, 136, 1404S-8S. DOI 10.1093/jn/136.5.1404S

- Weiss, B. 2012. Configuring the authentic value of real food: farm-to-fork, snout-totail, and local food movements. American Ethnology, 39, 614-626. DOI 10.1111/j.1548-1425.2012.01384.x

- Yen, A.L. 2009. Edible insects: Traditional knowledge or western phobia. Entomological Research, 39, 289-298. DOI 10.1111/j.1748-5967.2009.00239.x

- Zhu, Q., Sarkis, J., Lai, K. 2008. Confirmation of a measurement model for green supply chain management practices implementation. International Journal of Production Economics, 111, 261-273. DOI 10.1016/j.ijpe.2006.11.029 
- Zones, G., Mengistu, B.E., Regassa, N., Yusufe, A. 2009. The Levels, Determinants and Coping Mechanisms of Food Insecure Households in Southern Ethiopia. DCG Report No. 55. Ethiopia. 
